\title{
Three-dimensional Thermal and Dynamic Structure in Synoptic and Local Scale and its Influence on Haze Formation during Autumn in Beijing
}

\author{
Xiujuan Zhao ${ }^{1 *}$, Zhaobin Sun ${ }^{1}$, Yele Sun ${ }^{2}$, Ting Yang ${ }^{2}$, Dan Chen ${ }^{1}$, Ziming $\mathrm{Li}^{3}$, \\ Yajun Xiong ${ }^{3}$, Guiqian Tang ${ }^{2}$ \\ ${ }^{1}$ Institute of Urban Meteorology, Chinese Meteorological Administration, Beijing 100089, China \\ ${ }^{2}$ State Key Laboratory of Atmospheric Boundary Layer Physics and Atmospheric Chemistry, \\ Institute of Atmospheric Physics, Chinese Academy of Sciences, Beijing 100029, China \\ ${ }^{3}$ Environmental Meteorology Forecast Center of Beijing-Tianjin-Hebei, Beijing 100089, China
}

\section{ABSTRACT}

This study investigates the vertical thermal and dynamic structure of the atmosphere on synoptic and local scales from a three-dimensional perspective and its contribution to haze formation in Beijing during autumn. On a synoptic scale, the occurrence of heavy haze corresponds either to significant horizontal pollutant transport by southerly winds or to strong atmospheric vertical stability with downward air motion at altitudes below $\sim 1500-3000 \mathrm{~m}$; hence, meteorological parameters measured below $\sim 1500 \mathrm{~m}$ serve as better indicators of pollutant transport and dispersion than surface observations. When accompanied by increased southerly winds, the upward air motion between the ground and altitudes above $\sim 1500 \mathrm{~m}$ can transport pollutants from surrounding areas to Beijing, resulting in a rapid increase in $\mathrm{PM}_{2.5}$ (within several hours) despite weak winds on the surface, which confirms the possibility of regional transport during stagnant surface conditions and its potential role in haze formation.

Additionally, the mountain-plain breeze in the Beijing-Tianjin-Hebei (BTH) region during autumn drives strong local wind circulation, influencing the cumulative stage of haze episodes in this season. During the daytime, this breeze pushes pollutants to areas along the mountains and then to Beijing, resulting in a day-by-day increase in pollution. (By contrast, winter haze episodes arise from the accumulation of local pollution under stable meteorological conditions.) The combination of easterly winds and local topography can induce the formation and dissipation of haze, with the orographic effect propelling the haze into higher layers that host the transport of $\mathrm{PM}_{2.5}$ to the southeast. Afterward, southerly winds carry this pollution plume back along the mountain front, where it merges with surface pollutants through vertical mixing, finally this mixed plume arrived Beijing and contributes to the development of the next haze episode.

${ }^{*}$ Corresponding Author: xjzhao@ium.cn

Publisher:

Taiwan Association for Aerosol Research

ISSN: $1680-8584$ print

ISSN: 2071-1409 online

(c) Copyright: The Author(s).

This is an open access article distributed under the terms of the Creative Commons Attribution License (CC BY 4.0), which permits unrestricted use, distribution, and reproduction in any medium, provided the original author and source are cited.

Keywords: Haze formation, Vertical thermal and dynamic structure, Mountain-plain breeze circulation, Topographic effect

\section{INTRODUCTION}

Beijing, the capital city and the political and cultural center of China, suffers from frequent haze pollution in recent years, which has become one of the greatest issues of concern for the public and government (Zhao et al., 2011; Tao et al., 2014; Han et al., 2016; Huang et al., 2018). Therefore, extensive efforts have been made to characterize the source, properties, and formation processes of haze in Beijing. All kinds of emissions and the secondary formation of aerosols are main reasons for the severe haze events in Beijing (Liu et al., 2014; Sun et al., 2014). Besides, meteorology plays an important role in the causes of haze. Relative humidity, temperature inversion, and planetary boundary layer height (PBLH) are crucial factors in haze formation (Ye et al., 2016; Xu et al., 2017). 
Regional transport is considered to be an important factor for the rapid increase of PM (Ji et al., 2014; Sun et al., 2014). However, it is a debatable question on the role of regional transport in haze formation and there are strong arguments. Some observations have revealed that haze episodes in Beijing are mainly caused by the rapid secondary formation of PM, while the regional transport of PM is insignificant due to the weak wind under stagnant meteorological conditions (Guo et al., 2014; Han et al., 2016; Tang et al., 2016). Other studies illustrated that the regional transport of PM plays an important role in haze episodes. Using observational data, Zheng et al. (2015) indicated that the transition between clean and polluted air masses results in rapid reoccurrence of pollution from adjacent areas, rather than merely local chemical production. Modeling study also suggested regional transport plays a non-negligible role in haze episodes, with contributions of $14-31 \%$ to the surface $\mathrm{PM}_{2.5}$ mass concentration (Du et al., 2019). However, the observed data used in these studies were mainly measured on the ground. Hua et al. (2016) suggested that vertical meteorological and optical profiles are better to identify regional transport than merely ground-based observations. They analyzed three $\mathrm{PM}_{2.5}$ pollution episodes occurred sequentially in Beijing in November 2014 and confirmed the important influence of regional transport. In all these cases, PM is transported from south regions (where relatively polluted areas were located) to Beijing at high layer and then is brought to surface by downward motion. They also found a high PM layer still resided at $1000 \mathrm{~m}$ after the ending of first episode and then contributed to the sharp increase of PM in second episode. In Zhong et al. (2018), with ground and vertical meteorological data, 12 persistent heavy aerosol pollution episodes in Beijing were comprehensively analyzed and divided into two stages: the transport stage, characterized by pollutants being transported from the southern source region, and the cumulative stage, dominated by stable atmospheric stratification featuring slight or calm southerly winds, nearground anomalous inversion, and moisture accumulation. However, all pollution episodes in Zhong et al.'s (2018) study occurred in winter and the strong near-surface stability in this season positively enhanced the effect of local accumulation of PM (Guo et al., 2018; Su et al., 2018). Comprehensive analysis of autumn feature is still necessary.

In Beijing, the alternating atmospheric circulation from summer half-year to winter half-year usually occurs in early October, and leads to worse diffusion conditions, then results in heavy $\mathrm{PM}_{2.5}$ pollution episodes (Yin et al., 2019). This is probably one reason for the dramatic decrease in air quality from September to October in Beijing (Miao et al., 2012). Furthermore, thermal contrast between the mountain ranges and the plain is more significant in autumn than in other seasons, and leads to a prominent mountain-plain breeze circulation in the Beijing-Tianjin-Hebei (BTH) region (Miao et al., 2015). Haze pollution events usually occur when widespread stable conditions control most of North China Plain, while local circulation (mountain-plain breeze here) is non-negligible and may influence the evolution of haze during cumulative stage. However, the effects of these specific meteorological conditions on haze formation have not been well investigated, especially in a three-dimensional view. In addition, there are still some questions to be further addressed, built upon these cited studies. Does the PM transported from surrounding area only come from high layer or any possibility from lower layer? What is the detail formation process of the residual PM layer after the ending of first episode mentioned briefly in Hua et al. (2016), since it has evident contribution to the next episode?

In October 2014, four serious haze episodes occurred sequentially in Beijing. Yang et al. (2015) and Xu et al. (2017) analyzed the characteristics of chemical compositions of aerosols, unfavorable meteorological conditions, and the impact of regional transport for these four haze episodes. They indicated that secondary transformation, low PBLH, and increased water vapor were very important for haze formation. Biomass burning activities surrounding Beijing affected the first haze episode by regional transport. Chen et al. (2016) simulated variations of $\mathrm{PM}_{2.5}$, and sulfate, nitrate, and ammonium (SNA) concentrations in the four episodes by including $\mathrm{SO}_{2}-\mathrm{NO}_{2}-\mathrm{NO}_{3}$ relevant heterogeneous reactions in the Weather Research and Forecasting model coupled with chemistry (WRF-Chem), and confirmed the important contribution of heterogeneous reactions to the $\mathrm{PM}_{2.5}$ increase on polluted days. However, there was still an evident underestimation of SNA aerosols for peak values.

All of these studies presented good views of autumn haze formation using surface data, but the four haze episodes also provide useful changes in which to investigate the important effect of vertical structure on haze formation in autumn. Thus, we further investigated in this study the 
same period but with three-dimensional views. The characteristics and differences in the vertical meteorological structure in synoptic scale were first investigated during the four episodes, addressing the thermal and dynamic structure of the atmosphere and its contribution to haze development, regional transport, and accumulation of pollutants. Then the characteristics of local circulations caused by the interaction between the lower-level atmosphere and the topography, and its influence on haze evolution were investigated. The interaction caused the unusual ending of the second haze episode accompanied by southerly winds in contrast to the usual clean northerly winds, and produced an aloft PM layer around $1500 \mathrm{~m}$. This is similar as the resided PM layer observed by Hua et al. (2016). In order to illustrate this process more clearly, a simulation test was conducted finally with the chemical/dynamical regional model (WRF-Chem) from the beginning of the second episode to the end of the third. With observation and modeling, it was found that pollutants were actually aloft within the higher atmosphere (caused by the coupling effect of meteorology and topography) and may turn out to be the reason for the quick formation of the next haze episode at the surface.

\section{METHODS AND DATA}

\subsection{Field Observation}

Field observations were performed at the Institute of Atmospheric Physics (IAP; red triangle in Fig. 1(b)), Chinese Academy of Sciences $\left(39.95^{\circ} \mathrm{N}, 116.37^{\circ} \mathrm{E}\right)$, from 1 October to 12 November 2014. The IAP site is located in the northwest of Beijing city, approximately $40 \mathrm{~m}$ from the nearest traffic road to the north and $\sim 400 \mathrm{~m}$ from a busy highway to the east. The real-time measurements of meteorological variables, aerosols, and $\mathrm{PM}_{2.5}$ were conducted simultaneously.

The vertical particle extinction coefficient was measured by a dual-wavelength (1064 nm, $532 \mathrm{~nm}$ ) depolarization lidar (Sugimoto et al., 2001) The lidar can continuously observe aerosols below $6 \mathrm{~km}$ at 15-minute intervals under different weather conditions. The Fernald inversion method was applied to derive the extinction coefficient, with S1 set to $50 \mathrm{sr}$ in the inversion process (Fernald, 1984). The extinction coefficient at $532 \mathrm{~nm}$ was used in this study. Mixing layer height $(\mathrm{MLH})$ was retrieved from the measurement by a single-lens ceilometer (CL31; Vaisala, Finland) (Tang et al., 2015). We used the Vaisala software product BL-View to determine MLH by selecting the location with the maximum negative gradient in the attenuated backscattering coefficient profile as the top of the mixing layer (Emeis et al., 2012; Geiß et al., 2017). Because
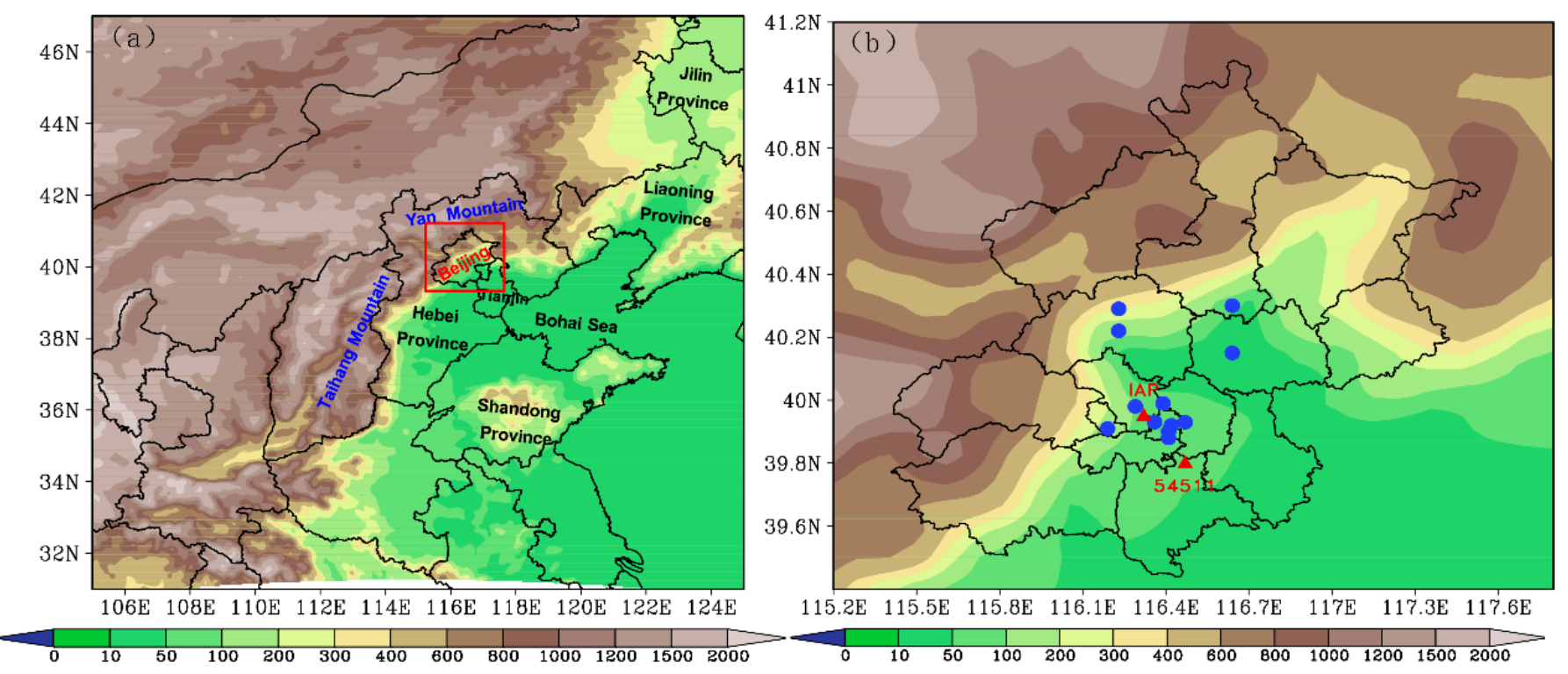

Fig. 1. Maps of (a) simulation domain and (b) 12 state-controlled stations (blue dots) with two measurement sites (red triangles: Institute of Atmospheric Physics (IAP) and meteorological Station 54511) in the Beijing area. Position of (b) is marked with red rectangle in (a). Shaded backgrounds are terrain heights $(\mathrm{m})$ illustrating the surrounding topography. 
the data are easily affected by noise and interference from the aerosol layering structure, time or space must be smoothly averaged before the gradient method can be used to calculate MLH (Münkel et al., 2007; Kotthaus et al., 2016). In this study, 240 m vertical, 1200 s time-smoothed averaging was applied by the BL-View software before analysis. Additional features of this algorithm, which is used in BL-View, are cloud and precipitation filtering and outlier removal.

Wind profiles from 100 to $5000 \mathrm{~m}$ were measured by a Doppler wind lidar (WindCube 200; Leosphere, Orsay, France). Wind speed (WS) and wind direction (WD) were obtained at 15 heights $(8,15,32,47,63,80,102,120,140,160,180,200,240,280$, and $320 \mathrm{~m})$ on the Beijing meteorological tower (BMT).

The size-resolved non-refractory submicron aerosol (NR-PM 1 ) species including organics, sulfate, nitrate, ammonium, and chloride were simultaneously measured at $260 \mathrm{~m}$ on the BMT and at ground level using an Aerodyne Aerosol Chemical Speciation Monitor from 15 October (Xu et al., 2015). The $\mathrm{PM}_{2.5}$ concentration on the ground was measured by a tapered element oscillating microbalance (Series 1400a; Thermo Scientific). A more detailed description of the sampling site and this experiment can be found in Sun et al. (2016).

\subsection{Supplementary Datasets}

The $\mathrm{PM}_{2.5}$ data over North China used in this study were taken from data released by the China National Environmental Monitoring Centre (http://106.37.208.233:20035/). The average $\mathrm{PM}_{2.5}$ of 12 sites within the Beijing area were selected as state-controlled stations to analyze the temporal variation of $\mathrm{PM}_{2.5}$ (blue dots in Fig. 1(b)).

Hourly meteorological data, wind direction, wind speed, temperature, and pressure were measured and recorded every hour in China, monitored by automatic meteorological stations (AMSs). There are about 2400 AMSs in China. The radiosonde data at the Beijing Meteorological Observatory were used to analyze the vertical variations of temperature, relative humidity, and wind. This station, Number 54511, is the only one in the Beijing area that participates in the international meteorological data exchange. The observation data at this station are used to represent meteorological conditions of the Beijing area. The wind profile, with a time resolution of 5 minutes, was observed with a boundary layer wind profile lidar at Station 54511 and used in the first haze episode (EP1: 7-11 October) due to the missing observation in the field experiment in this period.

All of the data in this study are reported in Beijing Standard Time (BST), except in Fig. 5, which uses Coordinated Universal Time (UTC). BST is equivalent to UTC plus 8 hours.

\subsection{WRF-Chem Simulation}

The WRF-Chem model was used to simulate the coupling effect of meteorology and topography on the spatiotemporal evolution of haze in this study. The model was run at $9 \mathrm{~km}$ horizontal resolution (Fig. 1(a)), with $223 \times 202$ grid points and 38 vertical layers from the surface to $50 \mathrm{hPa}$. The modeling domain covers the North China Plain and surrounding area $\left(30.66-47.07^{\circ} \mathrm{N}\right.$, $\left.104.34-128.47^{\circ} \mathrm{E}\right)$. Physical parameterizations included the following: urban canopy model (UCM), Noah land-surface model (Chen and Dudhia, 2001), Yonsei University scheme (YSU) for planetary boundary layer process (Hong et al., 2006), Grell-Devenyi ensemble convection, New Thompson et al. microphysics scheme (Thompson et al., 2008), Rapid Radiative Transfer Model (RRTM) longwave radiation scheme (Mlawer et al., 1997), and Goddard Space Flight Center shortwave radiation scheme (Chou et al., 1994). The Carbon-Bond Mechanism version Z (CBMZ) gas-phase chemical mechanism was selected because it includes more comprehensive reactions and alterable scenarios, and the Model for Simulating Aerosol Interactions and Chemistry (MOSAIC) aerosol mechanism was used with four size bins (Zaveri and Peters, 1999; Zaveri et al., 2008). Anthropogenic emission data were obtained from the Multi-resolution Emission Inventory for China (MEIC) for October 2008 (http://www.meicmodel.org/index.html) with a resolution of $0.1^{\circ}$ $\times 0.1^{\circ}$ (Zhang et al., 2009). The emission values were extrapolated to $9 \mathrm{~km}$ grids. The final analysis $(\mathrm{FNL})$ data with a resolution of $1.0^{\circ} \times 1.0^{\circ}$ from the National Centers for Environmental Prediction (NCEP) were used to provide meteorological initial and lateral boundary conditions (ICs and LBCs). The ICs and LBCs for chemistry are based on prescribed idealized profiles and background concentrations of gases and aerosols. Detailed information regarding the parameters used in the 
WRF-Chem model, such as the PBL scheme, the land surface scheme, the microphysics scheme, the cumulus cloud scheme, and chemical mechanism, can be found at the WRF website (http://www.wrf-model.org/index.php) and the WRF-Chem website (http://ruc.noaa.gov/wrf/w rf-chem/References/WRF-Chem.references.htm). The simulation started at 08:00 on 16 October and the first 4 days were treated as a spin-up period and were not used in our analysis.

\section{INFLUENCE OF THREE-DIMENSIONAL THERMAL AND DYNAMIC CONDITIONS IN SYNOPTIC SCALE ON HAZE FORMATION}

\subsection{General Characteristics}

The time series of $\mathrm{PM}_{2.5}$ concentration, visibility, and meteorological parameters during the study period are shown in Fig. 2. The hourly $\mathrm{PM}_{2.5}$ concentration observed at IAP agreed well with the averaged $\mathrm{PM}_{2.5}$ at 12 state-controlled stations, and was used to analyze the temporal variation of $\mathrm{PM}_{2.5}$. The four severe haze episodes, marked as EP1, EP2, EP3, and EP4 in Fig. 2, were characterized by continuous growth and high mass loading of $\mathrm{PM}_{2.5}$ accompanied by low visibility (less than $10 \mathrm{~km}$ ), and occurred during 7-11 October, 17-20 October, 22-25 October, and 29 October-1 November, respectively. The most severe episode was EP1, with the highest PM2.5 concentration of $263.6 \mu \mathrm{g} \mathrm{m}^{-3}$ and the lowest visibility of $1.8 \mathrm{~km}$, and lasted 5 days (Table 1). The highest hourly $\mathrm{PM}_{2.5}$ concentration of $439.0 \mu \mathrm{g} \mathrm{m}^{-3}$ was observed for EP3. The average $\mathrm{PM}_{2.5}$ concentration of EP3 was $217.0 \mu \mathrm{g} \mathrm{m}^{-3}$ and visibility was $2.6 \mathrm{~km}$. EP2 was the third most intensive haze period and EP4 the weakest.

The formation of these four episodes was strongly associated with stagnant meteorological conditions (Fig. 2). The surface wind was controlled by the local mountain-plain circulation. Southerly and northeasterly winds were prevailing during the day and night, respectively. The

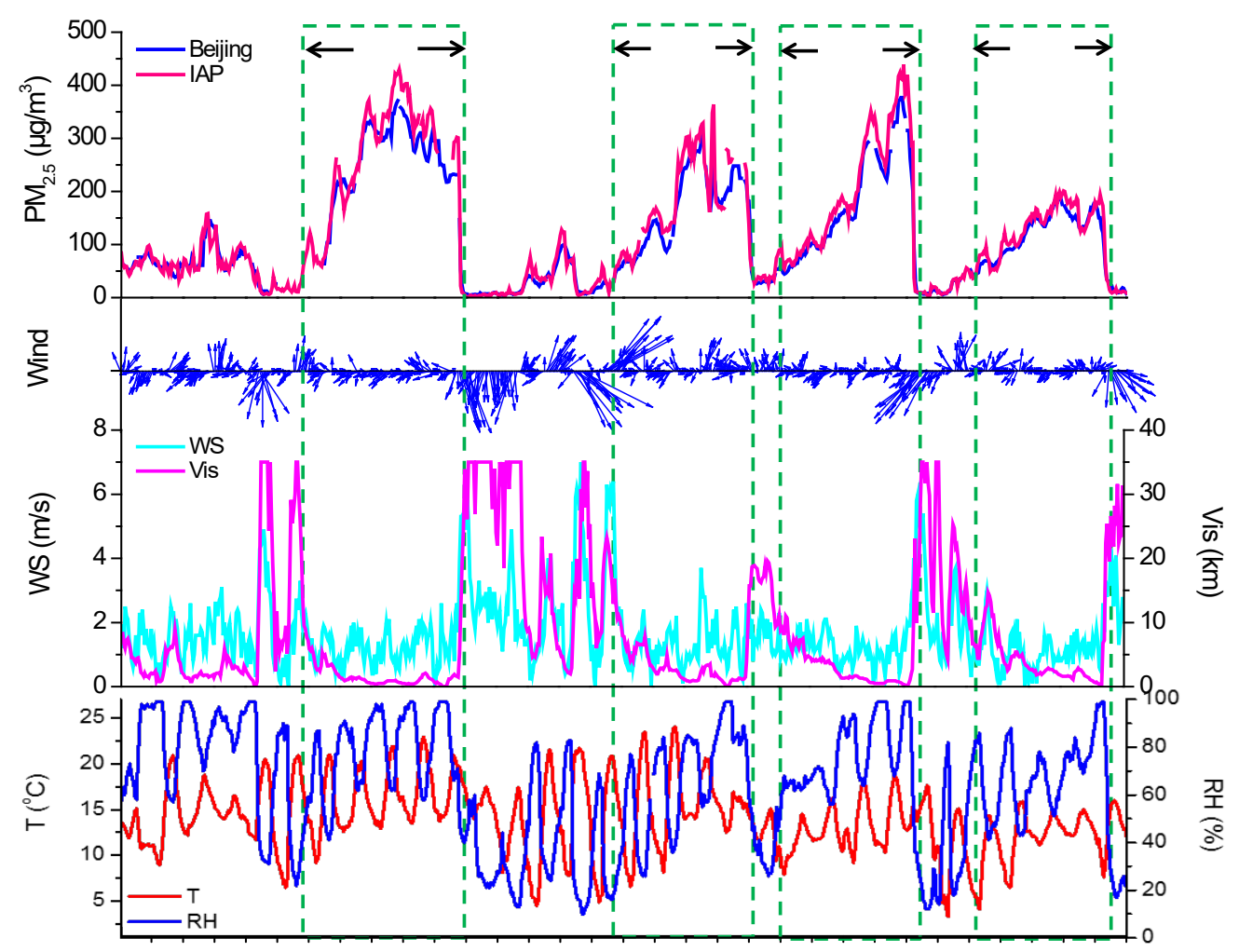

Fig. 2. Temporal variations of observed $P M_{2.5}$ (Beijing: average $P M_{2.5}$ of 12 state-controlled stations; Institute of Atmospheric Physics [IAP]: observed $\mathrm{PM}_{2.5}$ at IAP), wind vector, wind speed (WS), visibility (Vis), temperature ( $\mathrm{T})$, and relative humidity $(\mathrm{RH})$ at IAP from 1 October to 1 November 2014. 
Table 1. Average, minimum ( $P M_{2.5}$ Min), and maximum ( $\mathrm{PM}_{2.5}$ _Max) $\mathrm{PM}_{2.5}$ concentration, and averages of visibility and meteorological parameters during four haze episodes at IAP.

\begin{tabular}{|c|c|c|c|c|c|c|c|c|}
\hline & $\begin{array}{l}\mathrm{PM}_{2.5} \\
\left(\mu \mathrm{g} \mathrm{m}^{-3}\right)\end{array}$ & $\begin{array}{l}\text { PM }_{2.5 \_M i n} \\
\left(\mu \mathrm{g} \mathrm{m}^{-3}\right)\end{array}$ & $\begin{array}{l}\mathrm{PM}_{2.5}{ }^{-M a x} \\
\left(\mu \mathrm{g} \mathrm{m}^{-3}\right)\end{array}$ & $\begin{array}{l}\text { Vis } \\
(\mathrm{km})\end{array}$ & $\begin{array}{l}\text { WS } \\
\left(\mathrm{m} \mathrm{s}^{-1}\right)\end{array}$ & $\begin{array}{l}\mathrm{T} \\
\left({ }^{\circ} \mathrm{C}\right) \\
\end{array}$ & $\begin{array}{l}\mathrm{RH} \\
(\%)\end{array}$ & $\begin{array}{l}\text { Hours } \\
(\mathrm{RH}>90 \%)\end{array}$ \\
\hline EP1 & 263.6 & 59.0 & 430.0 & 1.8 & 1.3 & 16.3 & 77.9 & 38 \\
\hline EP2 & 170.3 & 56.0 & 364.0 & 2.9 & 1.3 & 15.4 & 67.9 & 11 \\
\hline EP3 & 217.0 & 61.0 & 439.0 & 2.6 & 1.2 & 13.3 & 77.5 & 27 \\
\hline EP4 & 144.6 & 52.0 & 201.0 & 2.9 & 1.0 & 12.2 & 70.6 & 7 \\
\hline
\end{tabular}

wind was very weak, with an average wind speed of about 1.0-1.3 $\mathrm{m} \mathrm{s}^{-1}$. Due to the change of season from autumn to winter, the average temperature decreased from EP1 to EP4. The average RH of EP1 and EP3 was high at $77.9 \%$ and $77 \%$, and hourly $\mathrm{RH}$ of more than $90 \%$ persisted for 38 and 27 hours, respectively. High RH is a very important factor in the formation of haze, by accelerating the chemical transformation of secondary pollutants and leading to hygroscopic growth of aerosols (Yang et al., 2015). During EP1 to EP4, there also seemed to be a strong response between $\mathrm{RH}$ and the level of $\mathrm{PM}_{2.5}$ concentration in these four episodes. With increased $\mathrm{RH}$, the secondary formation of aerosols promotes haze pollution (Quan et al., 2015; Liu et al., 2019). Except for $\mathrm{RH}$, there was no significant difference in surface meteorological parameters among the four episodes. To find the primary factors influencing each episode, a three-dimensional structure of meteorological variations is analyzed with vertical observation data.

\subsection{Influence of Vertical Thermal and Dynamic Conditions on Haze Formation}

To reveal the influence of vertical conditions on haze formation, vertical profiles of temperature and wind are presented in Figs. 3 and 4. According to the vertical characteristics of meteorological elements, the four episodes can be divided into two groups. EP1 and EP4 had double inversion layers of temperature, prevailing southerly winds under $3000 \mathrm{~m}$, and a widespread layer of descending air (positive vertical velocity in the pressure coordinate) above $900 \mathrm{hPa}$. In EP2 and EP3, only one evident inversion layer of temperature was observed. Southerly winds were mainly at a low level and alternated with northerly winds above $\sim 1500 \mathrm{~m}$, especially in EP3. A strong descending layer was located around 900-700 hPa in EP3, while in EP2 upward motion (negative vertical velocity in the pressure coordinate) existed below $500 \mathrm{hPa}$.

In spite of these similarities in thermal layering and wind distribution, the $\mathrm{PM}_{2.5}$ concentrations in EP1 and EP3 are significantly higher than in EP4 and EP2. In order to analyze the features of vertical thermal and dynamic conditions in each haze episode, we calculated the average vertical velocity from 850 to $750 \mathrm{hPa}$, where descending motion is most evident (Fig. 4), and the average meridional ( $v$ ) wind component (south-north wind) below $1500 \mathrm{~m}$, where southerly winds prevailed, for the four haze episodes. In the vertical direction, the descending motion and inversion hindered upward diffusion of pollutants and caused accumulation of pollutants in the lower atmosphere. Southerly winds generally carry warm, relative moist air to Beijing and promote the formation of upper inversion layers (Luan et al., 2018). The average vertical velocity and $v$ wind component can be used to reflect the dynamic features. Inversion intensity, defined as temperature differences $(\Delta t)$ between the top and bottom of an inversion layer, is calculated for analysis of thermal conditions. The statistical results were calculated for the haze formation period (increased $\mathrm{PM}_{2.5}$ ) and are listed in Table 2. The time periods for statistical calculation are from 20:00 on 7 October to 08:00 on 11 October, 20:00 on 17 October to 20:00 on 19 October, 08:00 on 22 October to 20:00 on 25 October, and 20:00 on 28 October to 20:00 on 31 October. The average v component was the highest in EP1 and the maximum of average vertical velocity was in EP3. The strongest southerly winds in EP1 carried not only warm, moist air to Beijing, but also pollutants from the more polluted southern industrial regions. The strongest descending air in EP3 caused the heaviest inversion in EP3 $\left(6.69^{\circ} \mathrm{C}\right)$, which hindered the vertical diffusion of pollutants. The continuous descending motion kept pressing the air down and further formed a low inversion layer during the four episodes. Thermal and dynamic conditions were most stable in EP3. For EP2, the transport of warm air and pollutants was also important due to the higher southerly winds, but the evident ascending motion $\left(-0.204 \mathrm{~Pa} \mathrm{~s}^{-1}\right)$ enhanced the vertical diffusion of pollutants. The temperature inversion 
(a) EP1
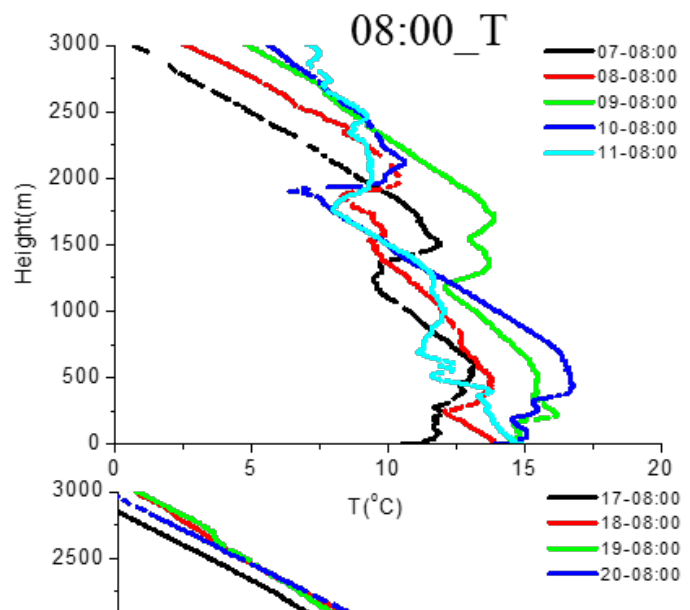

(b) EP2

(c) EP3

(d) EP4

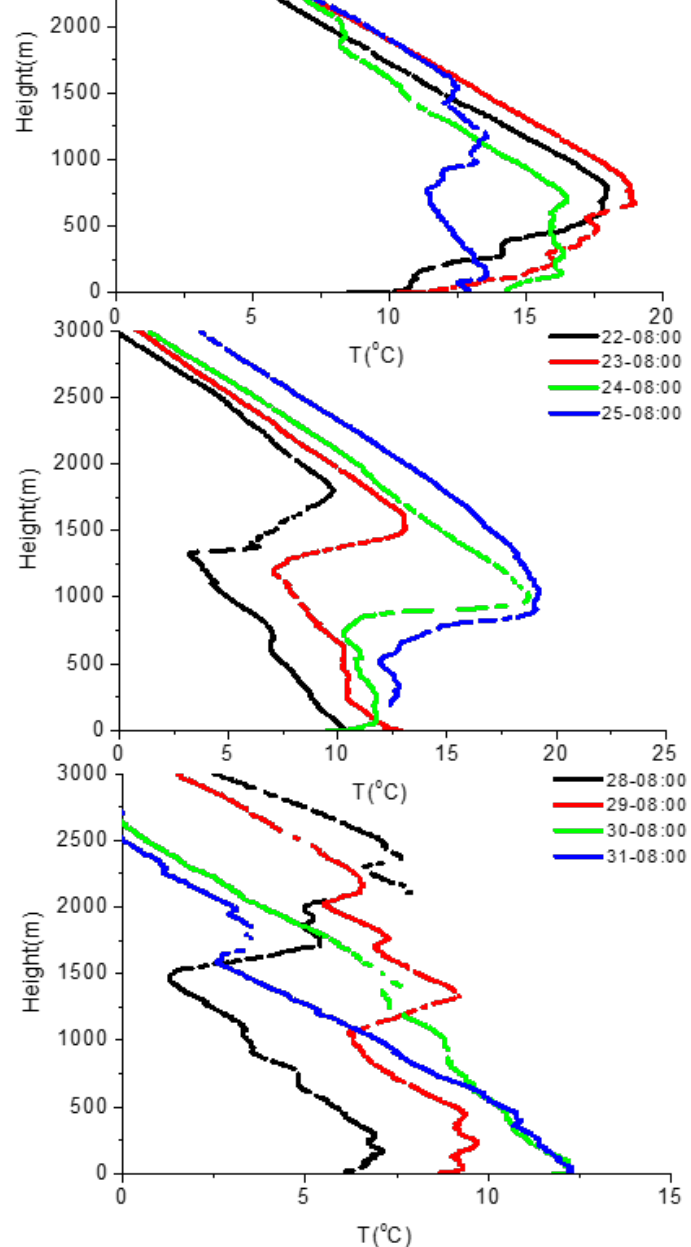

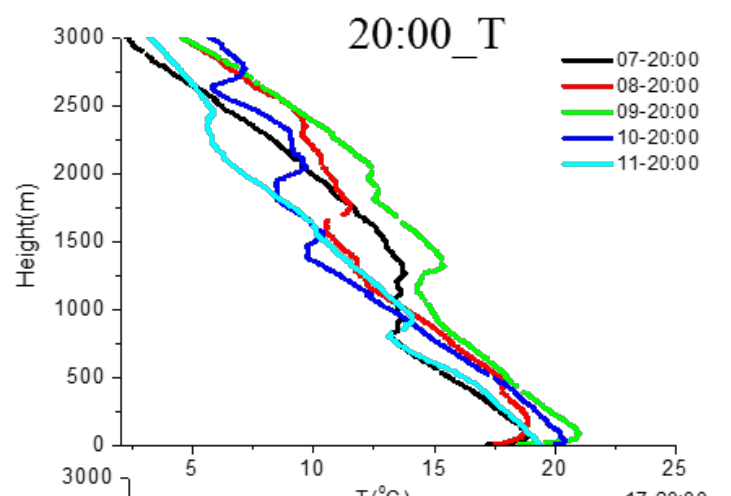
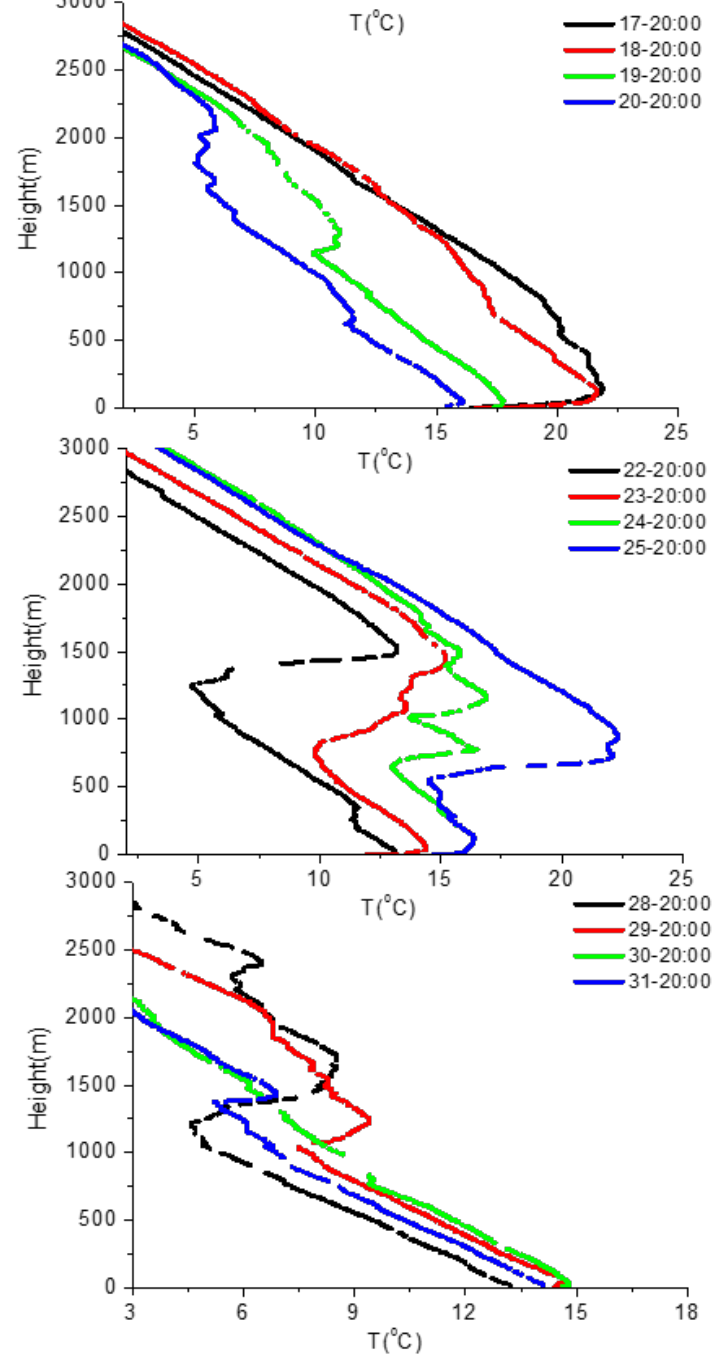

Fig. 3. Vertical distributions of observed temperature (T) at 08:00 and 20:00 at Station 54511 during four haze episodes.

in EP2 was higher than in EP1 and EP4, but it mostly occurred in the morning (08:00; Fig. 3(b)) and was erased in the daytime when the upward movement was enhanced from surface to $500 \mathrm{hPa}$ (20:00; Figs. 3(b) and 3(d)). The strongest ascending motion in EP2 restrained the rapid accumulation of pollutants to some extent. For EP4, the inversion was weakest and the horizontal transport and downward movement were not as prominent as in EP1 or EP3. Compared with the surface (Table 1), the average meteorological elements below $\sim 1500 \mathrm{~m}$ are better indicators of pollutant transport and dispersion. These indicators representing the effect of vertical meteorological conditions on haze formation have seldom been studied quantitatively before, and can potentially be used as early indictors for haze prediction to improve forecast skills. 

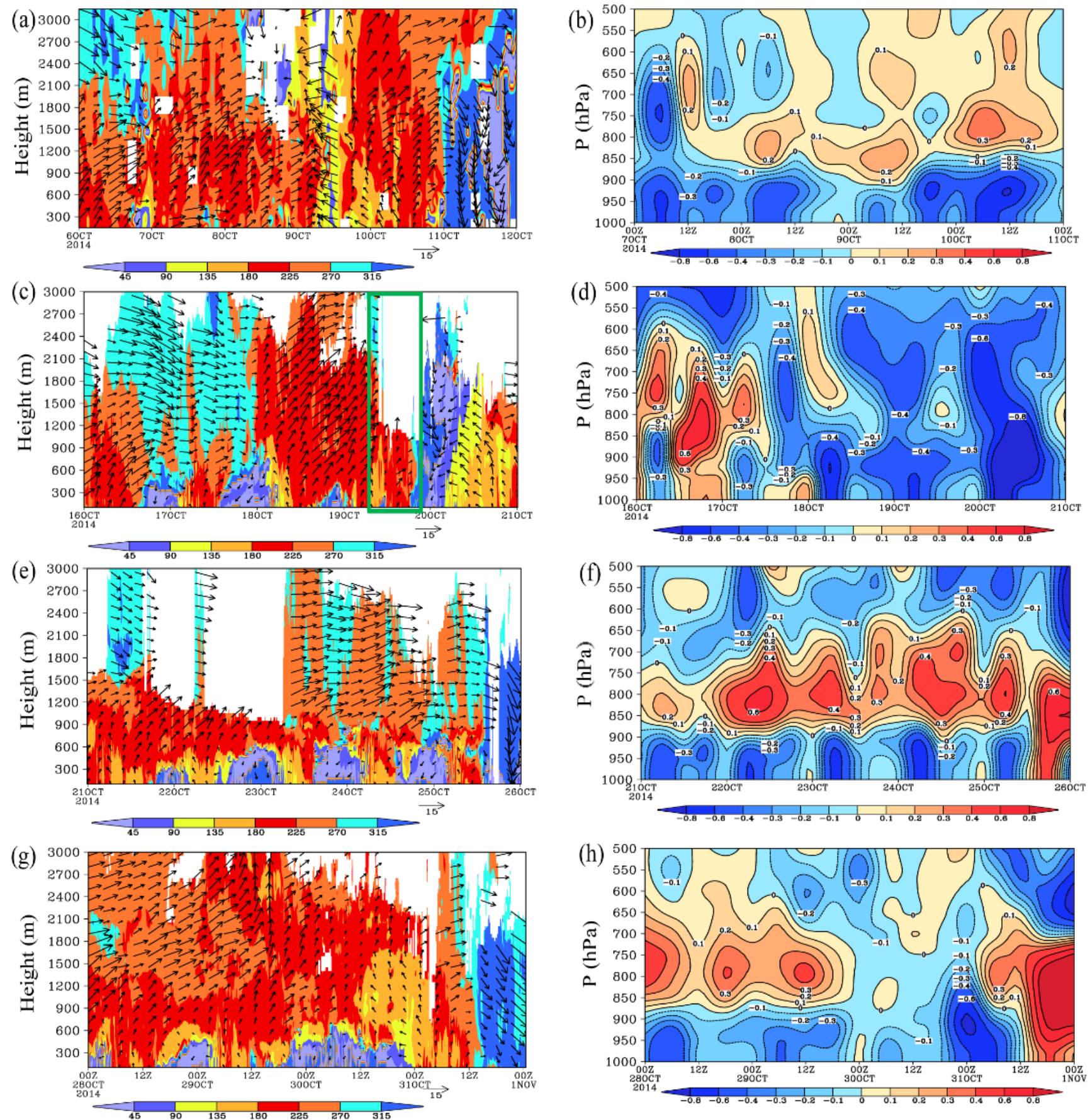

Fig. 4. Time-height distribution of observed horizontal wind vector $\left(\mathrm{m} \mathrm{s}^{-1}\right)$ and wind direction (shadings) by wind profile lidar, and time-pressure distribution of vertical velocity (shading with contour) obtained from final analysis (FNL) data (unit: $\mathrm{Pa} \mathrm{s}^{-1}$; negative and positive numbers stand for ascending and descending motion, respectively) during the four episodes: (a, b) EP1, (c, d) EP2, (e, f) EP3, and (g, h) EP4. Time is UTC.

Table 2. Average of meridional ( $\mathrm{v}$ ) component below $1500 \mathrm{~m}$ and vertical velocity from 850 to $750 \mathrm{hPa}$, and inversion intensity during the four episodes.

\begin{tabular}{llll}
\hline & v component $\left(\mathrm{m} \mathrm{s}^{-1}\right)$ & Vertical velocity $\left(\mathrm{Pa} \mathrm{s}^{-1}\right)$ & Inversion intensity $\left({ }^{\circ} \mathrm{C}\right)$ \\
\hline EP1 & 4.71 & 0.078 & 1.79 \\
EP2 & 3.90 & -0.204 & 2.72 \\
EP3 & 1.68 & 0.310 & 6.69 \\
EP4 & 2.54 & 0.107 & 1.40 \\
\hline
\end{tabular}




\subsection{Influence of Changes in Dynamic Conditions}

Fig. 5 shows the vertical distribution of the particle extinction coefficient and the variations of $\mathrm{PM}_{2.5}$ and MLH. On 7 October, MLH increased from $490 \mathrm{~m}$ at 06:00 BST to $1110 \mathrm{~m}$ at 09:00 BST, and then stayed near $1000 \mathrm{~m}$ until 20:00 BST. The $\mathrm{PM}_{2.5}$ concentration decreased while the mixing layer rose between 06:00 and 09:00 BST (i.e., rush hour), despite the higher emissions during this time. Then the $\mathrm{PM}_{2.5}$ began to increase rapidly while the MLH kept quite constant at a high level, which is marked with a shaded pink area in Fig. 5(a). In 11 hours (09:00-20:00), the $\mathrm{PM}_{2.5}$ concentration increased by $202 \mu \mathrm{g} \mathrm{m}^{-3}$, from 59 to $261 \mu \mathrm{g} \mathrm{m}^{-3}$, and the air quality in Beijing changed from moderately to severely polluted. Visibility was also reduced from 5.3 to $2 \mathrm{~km}$, and

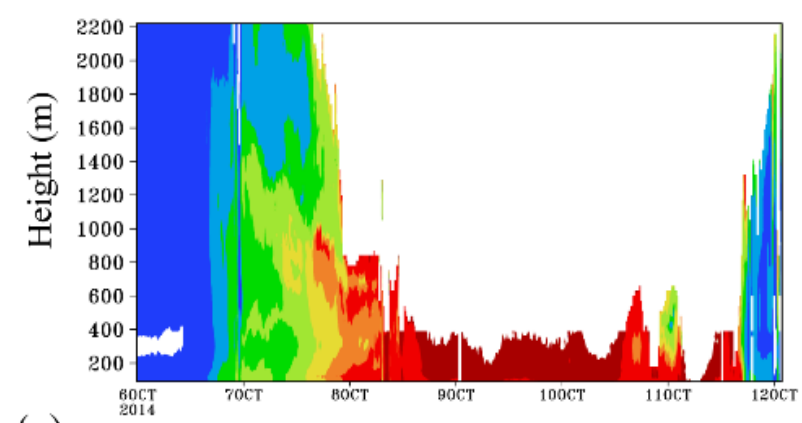

(a)
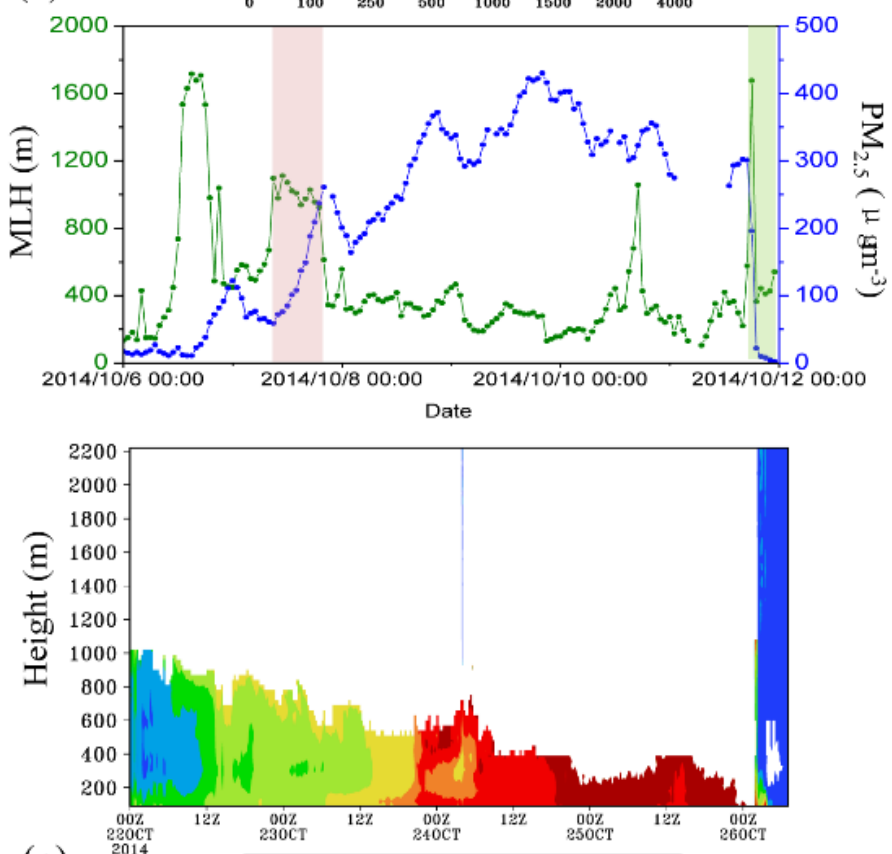

(c)

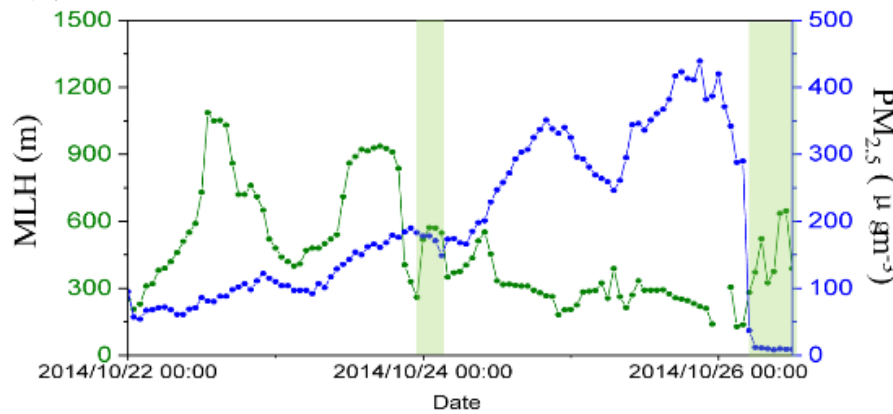

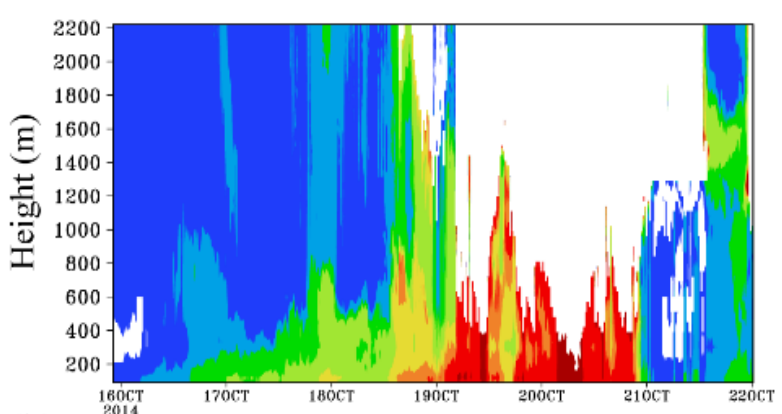

(b)
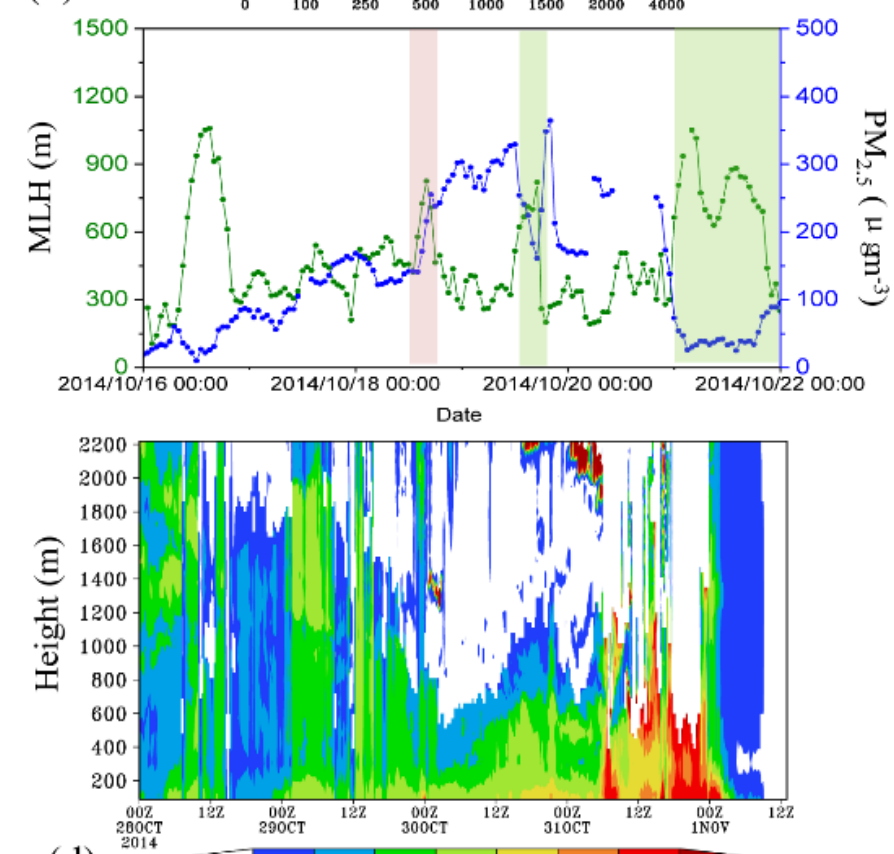

(d)

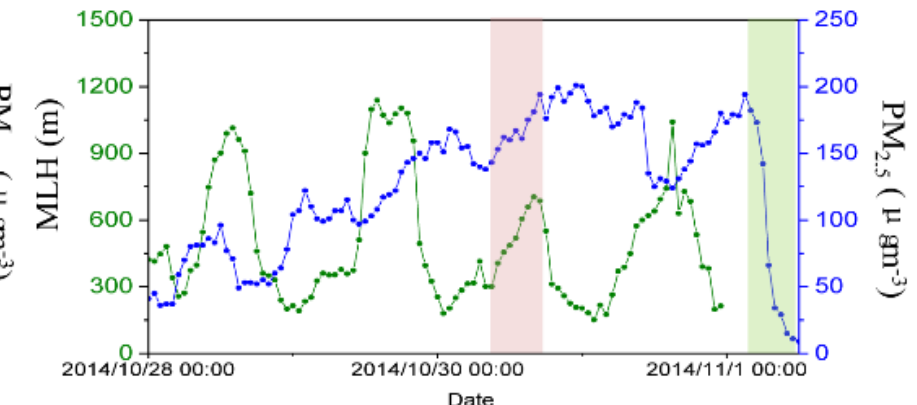

Fig. 5. Observed vertical distribution of particle extinction coefficient at $532 \mathrm{~nm}\left(\mathrm{Mm}^{-1}\right)$ and time series of $\mathrm{PM} 2.5$ and mixing layer height (MLH) (shaded pink area: simultaneous increases of $\mathrm{PM}_{2.5}$ and $\mathrm{MLH}$; shaded green area: decrease of $\mathrm{PM}_{2.5}$ accompanied by increase of MLH) for (a) EP1, (b) EP2, (c) EP3, and (d) EP4. 
serious haze conditions formed. As shown in Fig. 5(a), the particle extinction coefficient increased from the surface to about $1200 \mathrm{~m}$, and showed a higher value around 800-1000 m. Comparing Fig. 4(a) and 4(b), it can be seen that the ascending motion of the air from the surface to about $600 \mathrm{hPa}$ was enhanced after 10:00 and promoted the development of the boundary layer. At the same time, southwesterly winds were enhanced from the surface to about $1800 \mathrm{~m}$ and transported pollutants to Beijing quickly. Similar processes can also be observed in the afternoon of 18 and 30 October (northeasterly winds), with $\mathrm{PM}_{2.5}$ concentration increasing by 114 and $33 \mu \mathrm{g} \mathrm{m}^{-3}$ in 4 and 9 hours, respectively (shaded pink areas in Figs. 5(b) and 5(d)). The particle extinction coefficient increased consistently in the mixing layer. This regional transport process at the early stages of heavy haze events was addressed in recent studies. Most of this process is the increase of southerly winds with no anomalous inversion and striking moisture accumulation (Zhong et al., 2018). Our results indicate that this transport process is mainly caused by the changes of dynamic conditions in the entire mixing layer, although the meteorological conditions change little at the surface (Fig. 2). This explained the debatable arguments on regional transport under surface stagnant condition (namely, the regional transport is insignificant due to the weak wind under stagnant conditions while important during transition between clean and polluted air masses and in most haze episodes) and partially approved the previous assumption revealing the important role of regional transport in haze formation. In our study, this regional transport process also appeared in the middle stage of haze event, and the PM are transported to Beijing in entire mixing layer. This is different from those reported in previous studies (Hua et al., 2016; Zhong et al., 2018).

On the other hand, when changes of dynamic conditions in the whole layer bring northerly winds, this dilutes the pollutants and causes a sharp decrease of $\mathrm{PM}_{2.5}$ concentration and particle extinction coefficient, e.g., periods marked with a shaded green area in Fig. 5. In the afternoon of 19 October, the wind profiles show a layer of easterly winds (southeasterly winds at first and then changed to northeasterly winds) under $900 \mathrm{~m}$ and a layer of northerly winds between 1200-3000 m (green rectangle in Fig. 4(c); the top layer could be seen more clearly at Station 54511 with complete data), which indicated that dynamic conditions changed. Although the easterly wind only lasted for a short duration, it caused the evident decrease of $\mathrm{PM}_{2.5}$ in this period (first green shaded area in Fig. 5(b)). These temporary easterly winds do not transport pollutants too far; the wind direction turned rapidly southwestward (Fig. 4(c)) soon; pollutants were carried back and further increased the $\mathrm{PM}_{2.5}$ concentration (the sharp increase of $\mathrm{PM}_{2.5}$ from 18:00 to 21:00 on 19 October in Fig. 5(b)). Haze pollution is mostly cleaned by northerly winds, as also observed in our study. However, EP2 quickly ended around 00:00 on 21 October, accompanied by a southeasterly wind. The reason is addressed in detail with the model simulation in the following section.

\section{INFLUENCE OF THREE-DIMENSIONAL THERMAL AND DYNAMIC CONDITIONS IN LOCAL SCALE ON HAZE FORMATION}

\subsection{Circulation Convergence Caused by Mountain-plain Breeze and its \\ Contribution to the Aerosol Accumulation}

Except for the short duration of regional transport, most hazy days were associated with stagnant weather conditions characterized by low MLH (below 1000 m, or even below $500 \mathrm{~m}$ ) and mountain-plain circulation (Figs. 4 and 5). In general, the $\mathrm{PM}_{2.5}$ concentration in the Beijing urban area shows a bimodal pattern, with peaks in the morning and evening (Zhao et al., 2009). However, the increasing $\mathrm{PM}_{2.5}$ concentration during the day and slightly decreasing concentration at night on most hazy days (Fig. 5) show a unimodal pattern with a significant peak in the evening. This diurnal characteristic is similar to that of rural areas of Beijing, which are mainly influenced by the local mountain-plain breeze circulation (Zhao et al., 2009).

To analyze the effect of mountain-plain circulation, we selected EP3, where it was most significant compared with the others (Fig. 4(e)). The temporal variation of the chemical composition of PM1.0 at ground level and at $260 \mathrm{~m}$ and horizontal winds at 15 levels during EP3 are shown in Fig. 6. The aerosol composition $\left(\mathrm{SO}_{4}{ }^{2-}, \mathrm{NO}_{3}{ }^{-}, \mathrm{NH}_{4}{ }^{+}\right)$increased simultaneously at both levels accompanying the southerly winds (shaded green areas in Fig. 6), indicating that the transport occurred in the entire mixing layer. The surface wind field and variation of $\mathrm{PM}_{2.5}$ on 24 October (Fig. 7) shows 


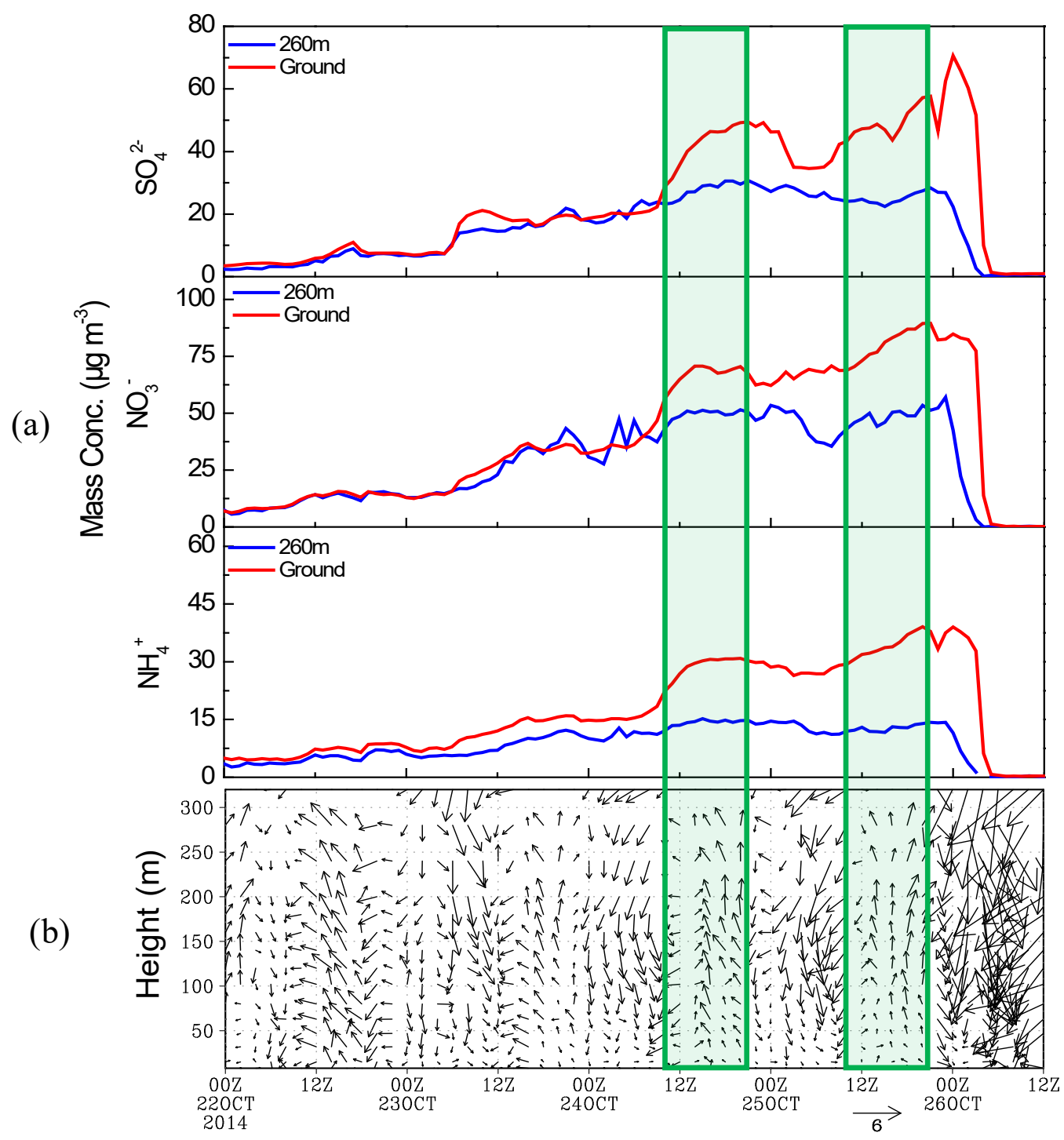

Fig. 6. Time series of (a) aerosol species at ground level and $260 \mathrm{~m}$, and (b) horizontal winds observed at 15 levels during EP3 at the IAP site.

that the wind speed increased in the northwest and southeast areas after sunrise, and the BeijingTianjin-Hebei region became a convergence area surrounded by stronger winds (Fig. 7(a)). The PM2.5 concentration rose in this area with the enhancement of convergence in the daytime (Fig. 7(b)). The surface wind field at 09:00 indicates that there was a convergence belt (red line in Fig. 7(a)) located to southeast of Beijing and stretching along the mountain. $\mathrm{PM}_{2.5}$ accumulated in this convergence belt. With the development of plain wind, the convergence belt began to move northward, and the $\mathrm{PM}_{2.5}$ in Beijing increased. From 07:00 to 09:00, pollutants were mainly transported from the east and southeast areas near Beijing (Fig. 7(c)), because the mountain winds first changed to easterly winds in the morning (Fig. 6(b)). As the convergence belt moved, the winds in Beijing changed to southerly and the wind speed increased gradually in the afternoon, and $\mathrm{PM}_{2.5}$ was constantly concentrated over Beijing (Fig. 7(c)). The transport process lasted until around 21:00 when the wind speed decreased and mountain winds began to form (Fig. 6). Thus, the decrease of both aerosols and $\mathrm{PM}_{2.5}$ was due to the reduced emissions and enhanced mountain winds at night. However, the northerly mountain wind in the nighttime was weaker than plain wind and did not stretch far from the mountain, which was similar to but weaker than that at 09:00 (not shown). The $\mathrm{PM}_{2.5}$ was not diluted effectively and still accumulated in front of the mountain. When the southerly plain wind enhanced in the daytime, it pushed the pollutants to the north mountain area and increased the $\mathrm{PM}_{2.5}$ concentration. This convergence process again 
(a)Wind field

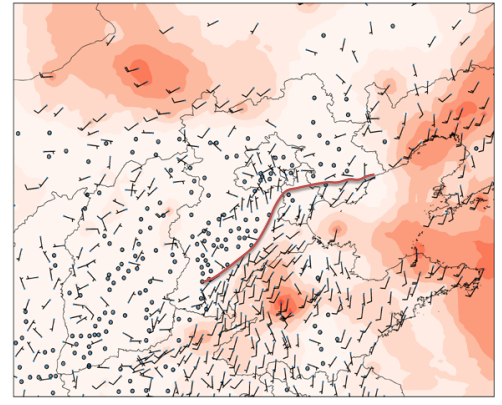

(b) $\mathrm{PM}_{2.5}$

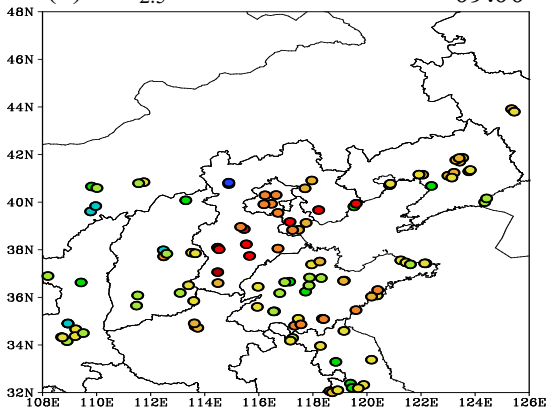

(c) $\triangle \mathrm{PM}_{2.5}$

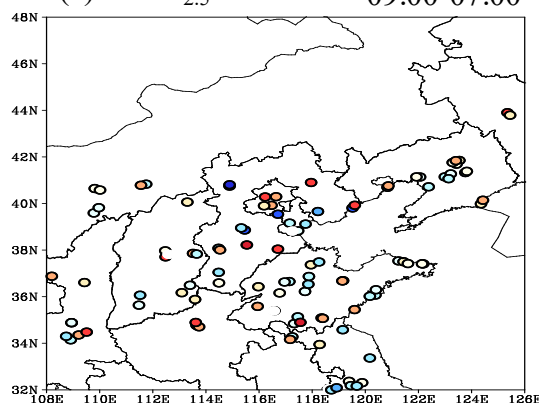

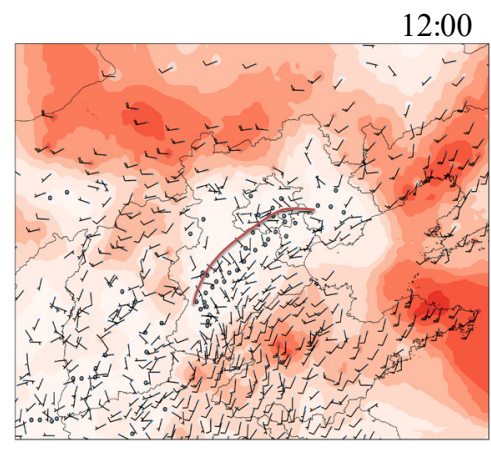

12:00

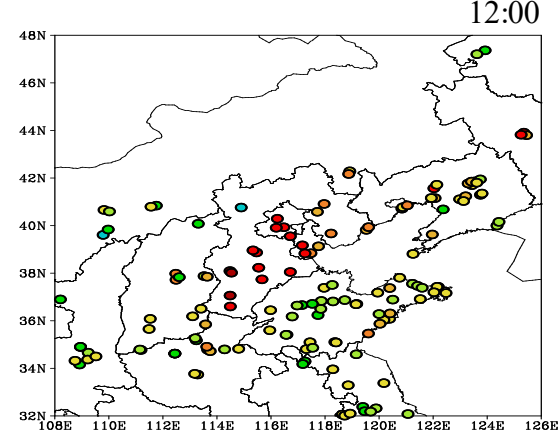

12:00-09:00

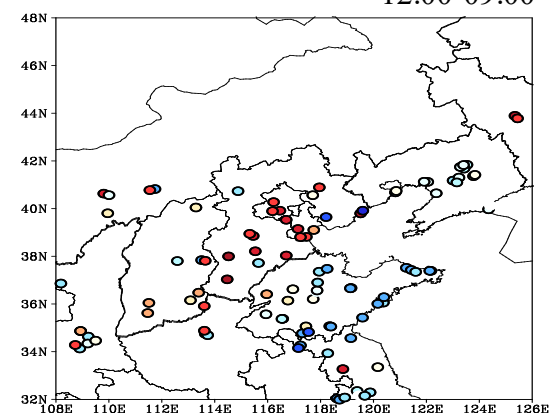

14:00

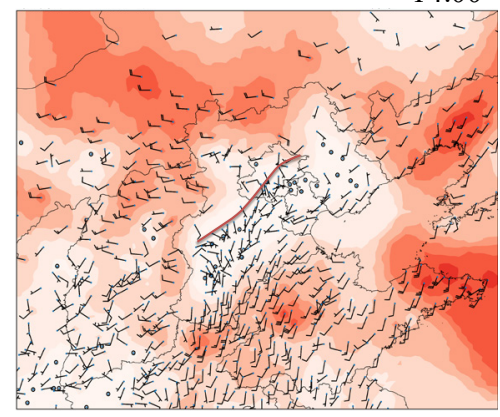

14:00

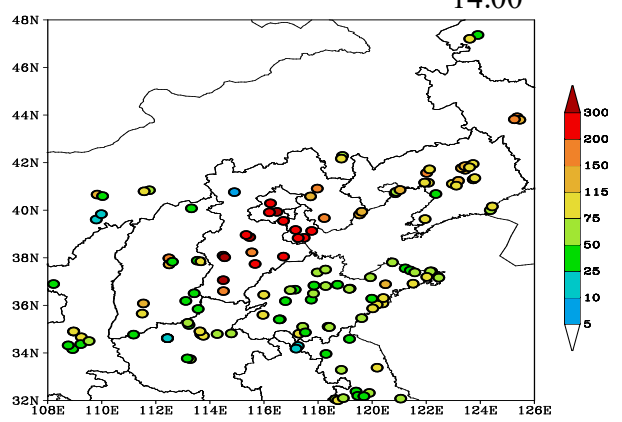

14:00-12:00

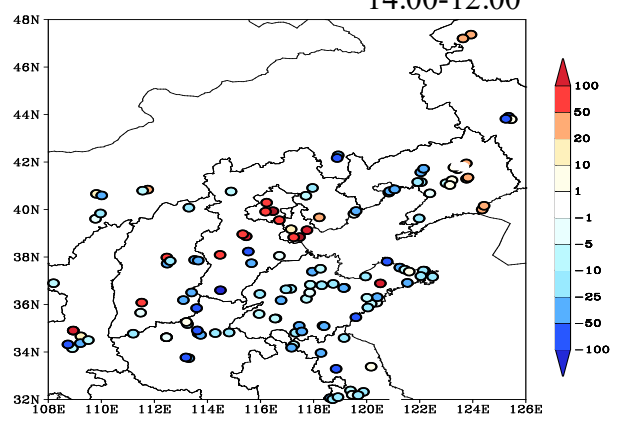

Fig. 7. Horizontal wind fields and $\mathrm{PM}_{2.5}$ concentrations at different times on 24 October: (a) wind fields (red shade: wind speed; red line: location of convergence belt), (b) $\mathrm{PM}_{2.5}$ concentrations, and (c) changes of $\mathrm{PM}_{2.5}$ concentrations (09:00-07:00 means $\mathrm{PM}_{2.5}$ concentration at 09:00 minus that at 07:00).

occurred on 25 October, when aerosols increased simultaneously at ground level and at $260 \mathrm{~m}$ during the day (09:00-15:00) when the plain winds strengthened (Fig. 6).

In the other three episodes, the convergence of pollutants induced by plain winds in the daytime can also be observed, and the $\mathrm{PM}_{2.5}$ increased mostly with increased or nearly unchanged MLH (Fig. 5). For example, increased $\mathrm{PM}_{2.5}$ occurred on 8, 23, and 29 October. The $\mathrm{PM}_{2.5}$ concentration showed a continuous increase with the development of the mixing layer in the daytime, and the morning peak even disappeared. If there is no transport of pollutants from outside, $\mathrm{PM}_{2.5}$ should decrease with the development of the boundary layer and have two peaks in the morning and evening (Zhao et al., 2009). Compared with the sharp increase of PM2.5 concentration induced by convergence on a synoptic scale, the increased speed of $\mathrm{PM}_{2.5}$ is lower due to the weak plain winds. Even the surface wind is weak in haze episodes, but the convergence induced by topography in the daytime can transport pollutants from surrounding areas to Beijing. At night, mountain wind, which is weaker than plain wind, dilutes the pollution less. Thus, the mountain-plain circulation pushes the pollutants to areas along mountains like tides, especially to the northernmost city, Beijing, and results in a day-by-day increase of pollutants during the day. This is different from observation in winter haze events that local pollution accumulation is the main cause for haze worsening in stable meteorological conditions (Zhong et al., 2018). In addition, this convergence causes not only the transport of pollutants but also humid and warm air, which promotes the 
secondary transformation of aerosols and the formation of low inversion layers, further enhancing haze pollution.

\subsection{Coupling Effect of Easterly Winds and Local Topography}

As mentioned above, the end of EP2 on 21 October was accompanied by southeasterly winds, not the usual northerly winds. The observation of the particle extinction coefficient showed that there was an elevated layer around $1500 \mathrm{~m}$ on 21 October (Fig. 5(b)). This layer descended slowly and integrated with the extinction layer near the surface. So EP2 and EP3 seemed to be connected by this layer. Observations and modeling results suggest that the reason for this phenomenon was the coupling effect of the easterly wind and local topography. Beijing was influenced by the base of the high-pressure system on 20 October. Northeasterly wind prevailed in Northeast China and was strengthened over the Northeast China Plain and Bohai Sea after 20:00 on 20 October (Fig. 8(b)). The wind was blocked by Yan Mountain and partly changed to an easterly wind, reaching Beijing along the mountain, and most wind passed over the Bohai Sea and cleared Tianjin, the southeast part of Hebei Province, and Shandong Province in advance. Thus, when the wind turned to the southeasterly direction at the end of EP2, it carried clean air and diluted the polluted air in Beijing (Figs. 8(d)-8(f)). The easterly wind (first easterly and then southeasterly) arrived in Beijing and gradually pushed the pollutants to the west. The concentration of $\mathrm{PM}_{2.5}$ decreased slowly from $200-250 \mu \mathrm{g} \mathrm{m}^{-3}$ ( 20:00 on 20 October) to below $50 \mu \mathrm{g} \mathrm{m}^{-3}$ ( 02:00 on 21 October) and became clean at about 04:00 on 21 October. The $\mathrm{PM}_{2.5}$ was not transported to the west of Beijing, where the concentration stayed at a low level all along. To analyze this dilution and the possible vertical mixing process, we used the WRF-Chem model to simulate the process.

Fig. 9 shows the time series of observed and simulated temperature, $\mathrm{RH}$, wind speed, wind direction and $\mathrm{PM}_{2.5}$ at IAP. The model is capable of capturing variations of $\mathrm{PM}_{2.5}$ and meteorological elements. The deficiencies in the meteorological simulation are underestimated relative humidity, especially in EP2, and overestimated wind speed and temperature. The simulated $\mathrm{PM}_{2.5}$ concentration is lower than that observed during the peak periods on 18, 20, 24, and 25 October. The underpredicted humidity and overestimated wind speeds could be among the reasons for the underestimation of $\mathrm{PM}_{2.5}$. The missing relevant $\mathrm{SO}_{2}-\mathrm{NO}_{2}-\mathrm{NO}_{3}$ heterogeneous reactions in the

17:00 Oct. 20

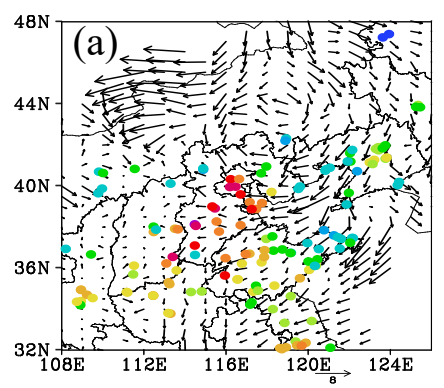

01:00 Oct. 21
20:00 Oct. 20

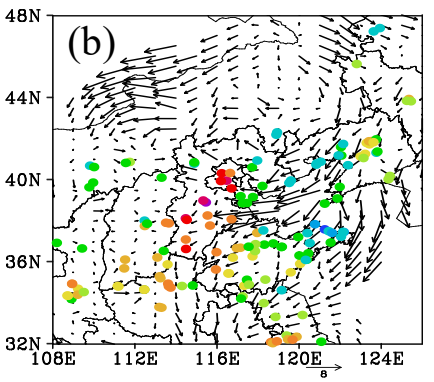

\section{0:00 Oct. 21}

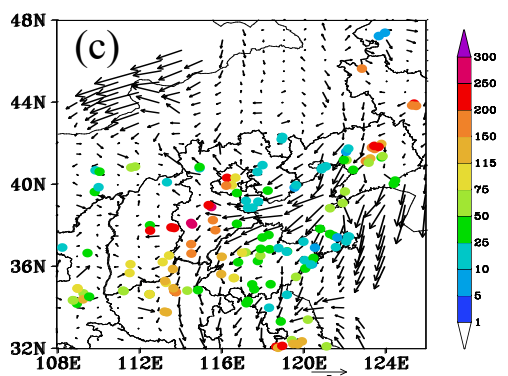

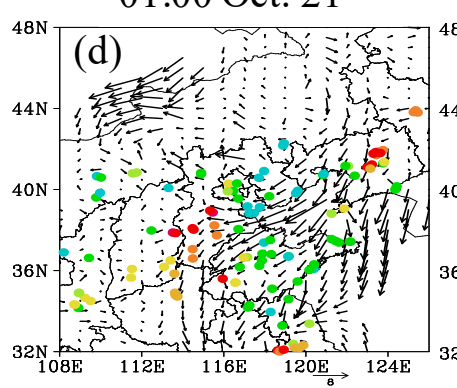

02:00 Oct. 21

04:00 Oct. 21
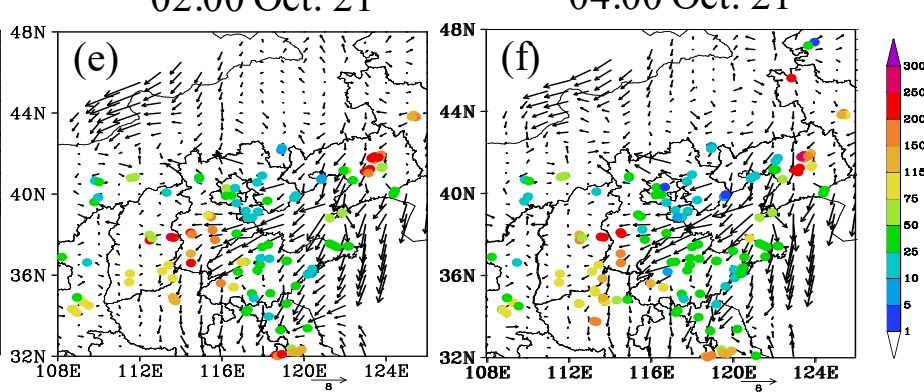

Fig. 8. Spatial and temporal variations of observed $\mathrm{PM}_{2.5}\left(\mu \mathrm{g} \mathrm{m}^{-3}\right.$; colored dots) and winds at typical times from 17:00 on 20 October to 04:00 on 21 October. 
(a)

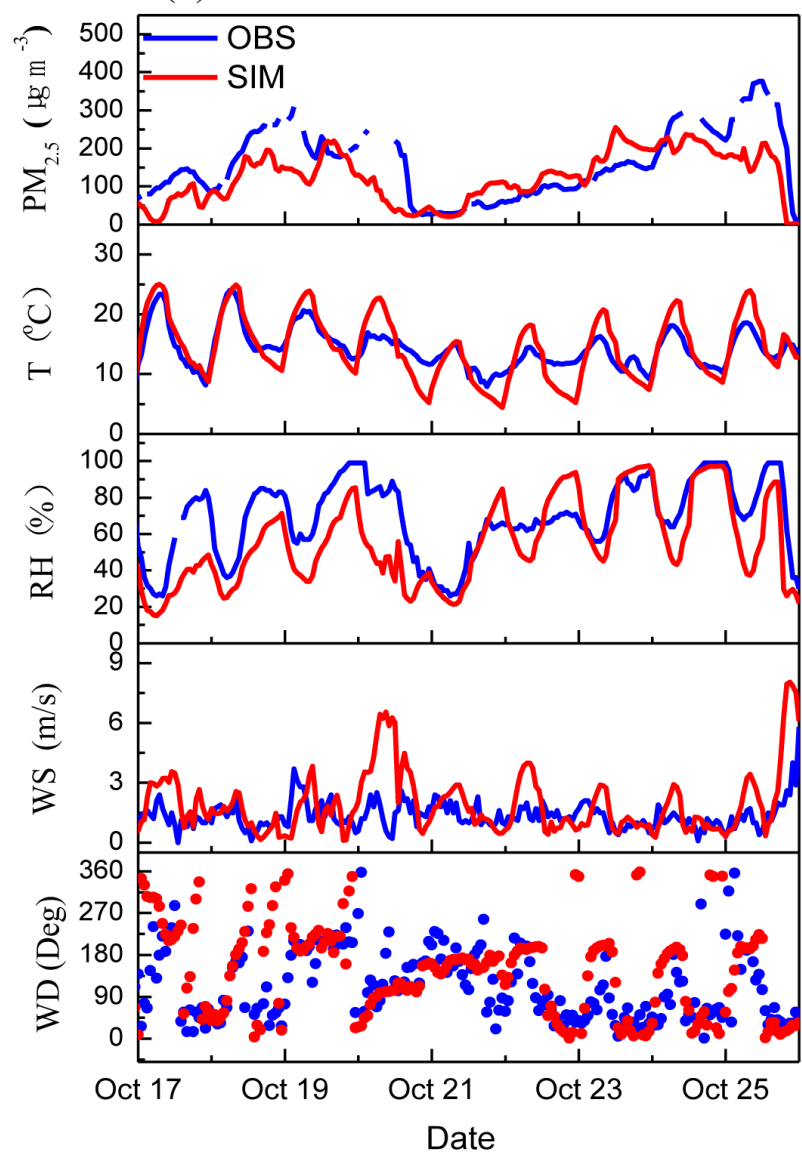

(b)

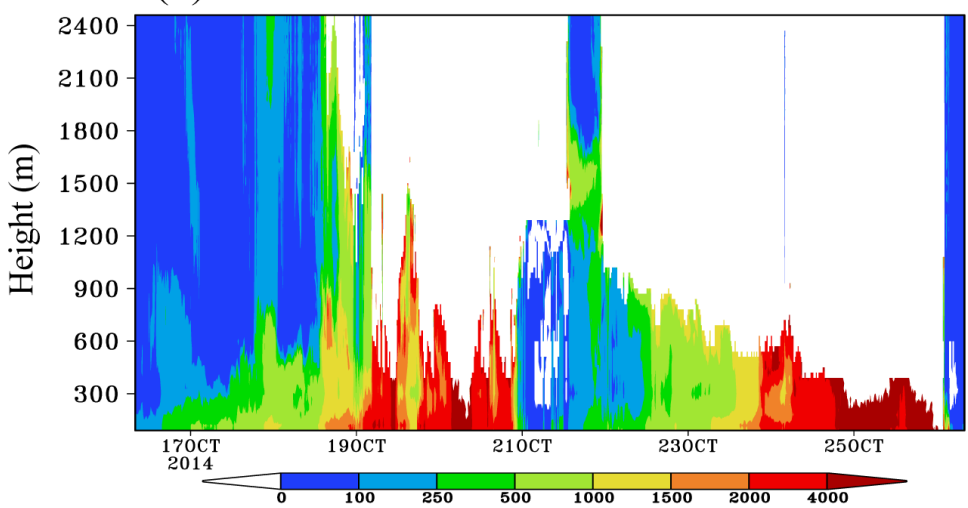

(c)

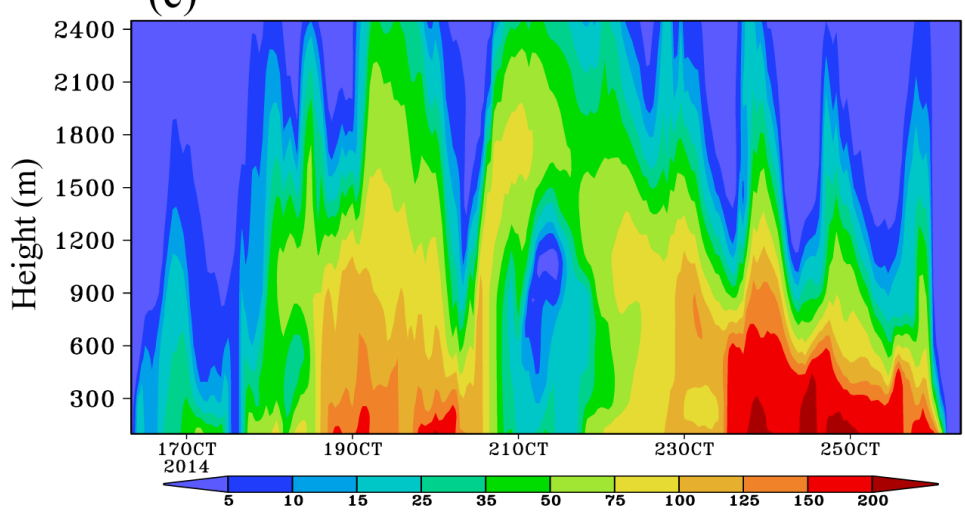

Fig. 9. Time series of (a) observed and simulated $\mathrm{PM}_{2.5}$ and meteorological parameters at IAP on the surface, (b) observed particle extinction coefficient $(532 \mathrm{~nm})$ at IAP $\left(\mathrm{km}^{-1}\right)$, and (c) simulated $\mathrm{PM}_{2.5}$ concentration $\left(\mu \mathrm{g} \mathrm{m}^{-3}\right)$ at IAP, 17-26 October.

current aerosol scheme in WRF-Chem are another important reason for this underestimation (Chen et al., 2016). Furthermore, emissions of pollutants in 2008 (used in this study) were generally lower than in 2014. The evolution of emissions from 2000 to 2015 in China showed that the primary aerosol and $\mathrm{NH}_{3}$ emissions in 2008 (used in this study) were slightly lower than in 2014. $\mathrm{SO}_{2}$ and $\mathrm{CO}$ emissions showed decreasing trends from 2008 to 2014, while $\mathrm{NO}_{x}$ and non-methane volatile organic compounds evidently increased (Li et al., 2017). The lower emissions partly resulted in the underestimation of $\mathrm{PM}_{2.5}$, but the model reproduced the vertical structure of haze well. The simulated vertical distribution of $\mathrm{PM}_{2.5}$ (Fig. 9(c)) agrees well qualitatively with the particle extinction coefficient observed by lidar (Fig. 9(b)). PM2.5 decreased significantly below $1500 \mathrm{~m}$ from $\sim 20: 00$ on 20 October to 12:00 on 21 October. At the same time, an elevated layer of $\mathrm{PM}_{2.5}$ appeared between 1500 and $1800 \mathrm{~m}$.

Longitudinal and latitudinal cross-sections of the modeled $\mathrm{PM}_{2.5}$ concentrations and wind vectors ( $\mathrm{u} / \mathrm{v}$ and $\mathrm{w} \times 100$ ) along $39.95^{\circ} \mathrm{N}$ and $116.37^{\circ} \mathrm{E}$ for selected hours toward the end of EP2 and the beginning of EP3 are plotted in Figs. 10 and 11, respectively. The first three cross-sections $\left((a)-(c)\right.$ in both figures) show that the $P_{2} M_{2.5}$ was blocked by the mountains, resulting in easterly and southerly winds, then was raised and transported along with them, and finally appeared as an elevated layer 1200-2400 m southeast of the mountains. A high PM2.5 concentration center appeared with a vertical circulation in front of the mountains. The $\mathrm{PM}_{2.5}$ was clean at ground level and the EP2 seemed to end. After several hours (Figs. 10(d) and 11(d)), the PM2.5 plume was transported to the southeast by the northwesterly winds and part of it was brought to the surface around $35-36^{\circ} \mathrm{N}$ by the descending motion. Then, the $\mathrm{PM}_{2.5}$ was carried back to Beijing as the winds changed to a southerly direction and began to increase along the mountain from the surface to $1200 \mathrm{~m}$ (Figs. 10(e)-10(g) and 11(e)-11(g)), and finally merged with the upper layer by 

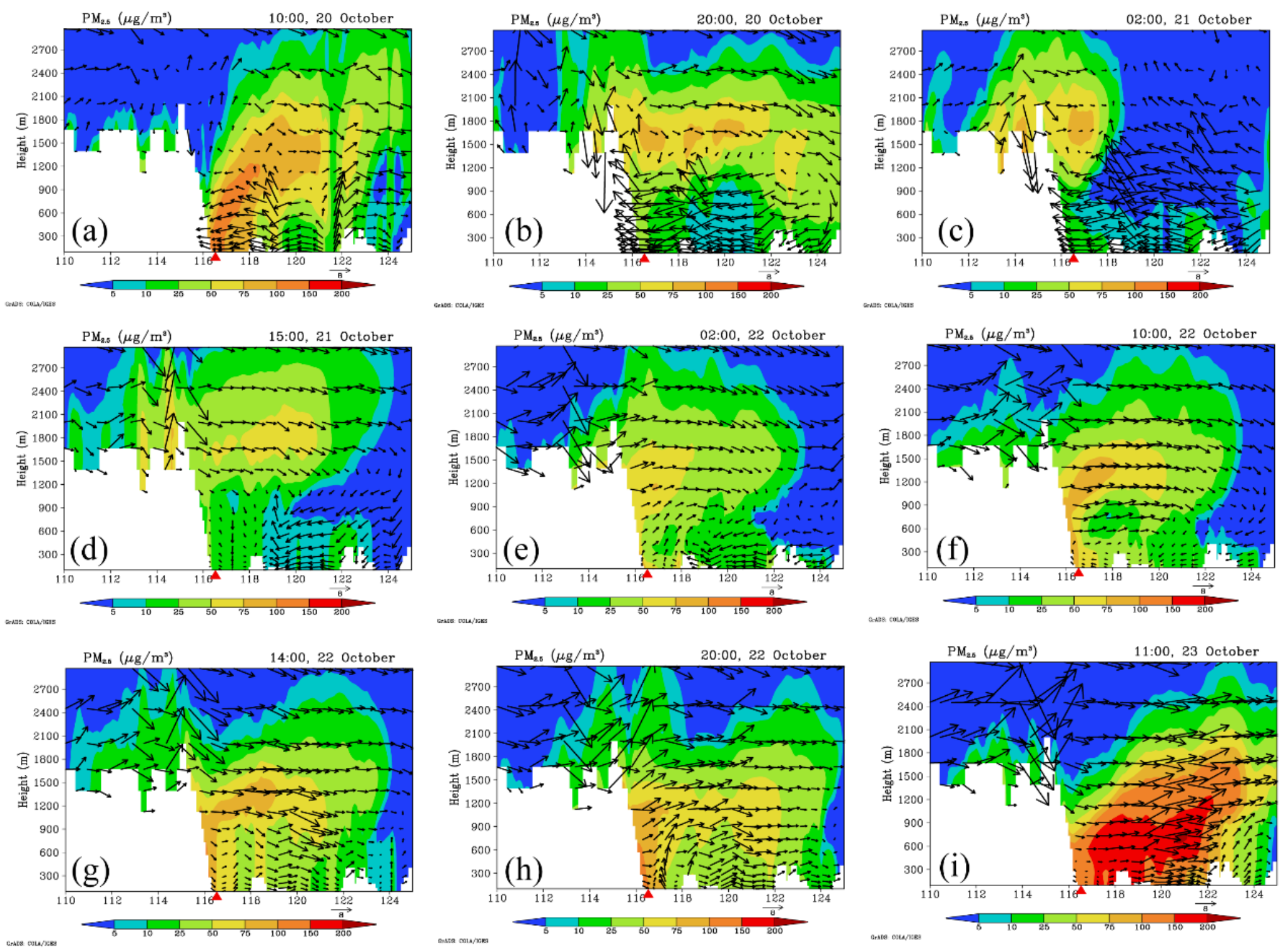

Fig. 10. Longitudinal cross-sections of modeled $\mathrm{PM}_{2.5}$ concentration and wind vector ( $\mathrm{u}$ and $\mathrm{w} \times 100$ ) along $39.95^{\circ} \mathrm{N}, 20-23$ October (red triangle: IAP site).

descending motion (Figs. 10(h) and 11(h)). The $\mathrm{PM}_{2.5}$ concentration increased in the lower layer due to accumulation and transportation by the southerly winds (Figs. 10(i) and 11(i)). The EP3 formed gradually. These downward mixing processes enhanced the severe haze during the next 2 days of EP3. This special dissipation and formation process caused by the coupling effect of easterly winds and local topography have not been thoroughly investigated before, especially in a three-dimensional view.

\section{CONCLUSIONS}

Using comprehensive observational vertical data from four severe haze episodes that occurred sequentially in Beijing and the surrounding areas during autumn 2014 as well as model simulations of the relevant mechanisms, we analyzed the vertical thermal and dynamic structure of the atmosphere on synoptic and local scales to evaluate its effect on haze formation processes, including the regional transport and accumulation of pollutants, from a three-dimensional perspective.

On a synoptic scale, the occurrence of heavy haze corresponds to extremely adverse thermal and dynamic atmospheric conditions below altitudes of $\sim 1500-3000 \mathrm{~m}$, such as the prevalence of southerly winds that horizontally transport pollutants, or a high degree of vertical stability paired with downward air motion, which inhibits vertical diffusion. Thus, meteorological parameters at altitudes below $\sim 1500 \mathrm{~m}$ act as better indicators of pollutant transport and dispersion than 

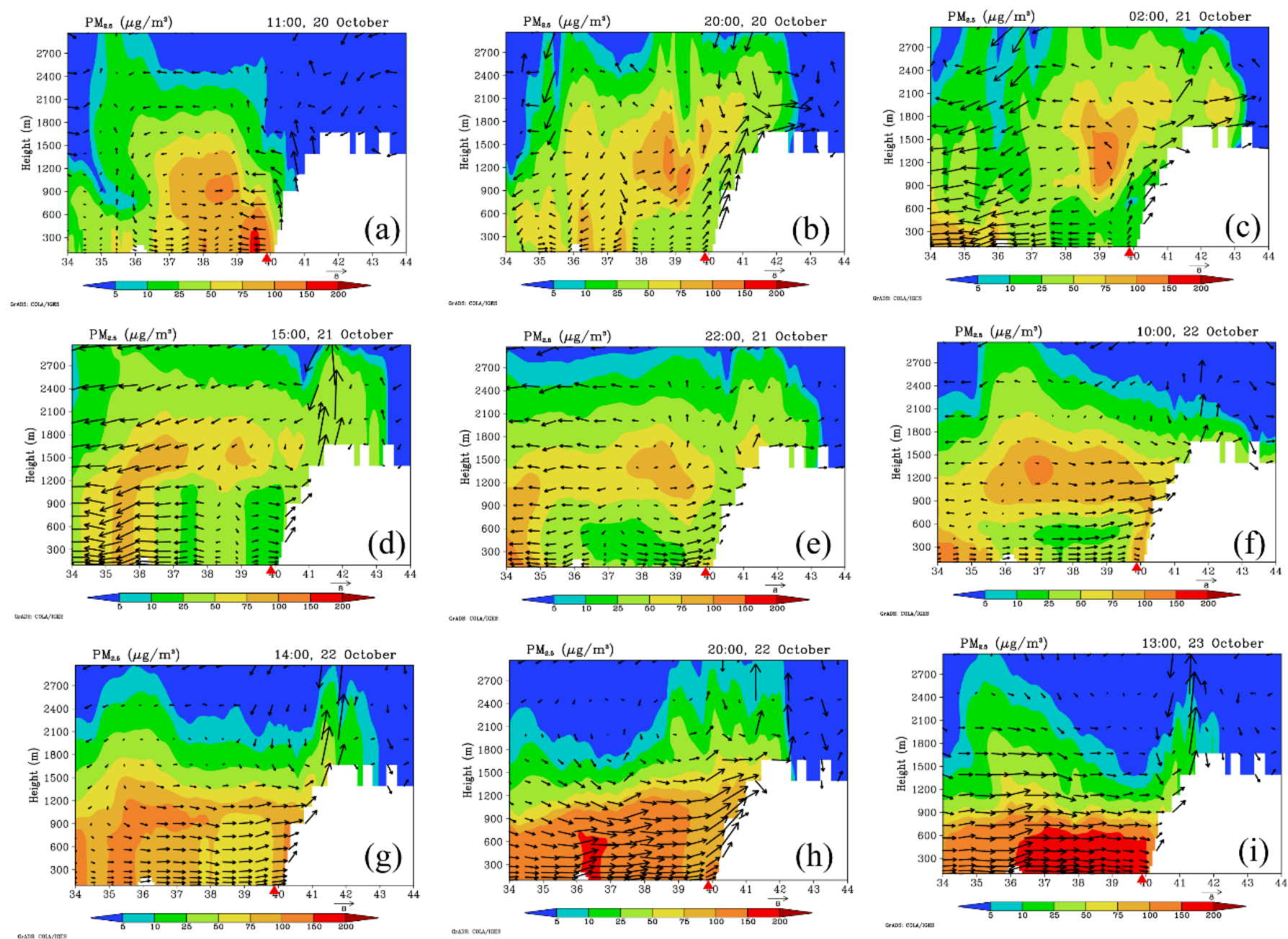

Fig. 11. Latitudinal cross-sections of modeled $\mathrm{PM}_{2.5}$ concentration and wind vector $(v$ and $w \times 100)$ along $116.37^{\circ} \mathrm{N}, 20-23$ October (red triangle: IAP site).

surface measurements. In combination with increased southerly winds, the upward air motion between the ground and altitudes above $\sim 1500 \mathrm{~m}$ can transport pollutants from surrounding areas to Beijing, resulting in a rapid increase in $\mathrm{PM}_{2.5}$ (within several hours) and exacerbated haze despite weak winds on the surface, which confirms the possibility of regional transport during stagnant surface conditions and its potential role in haze formation. Thus, these meteorological conditions, although seldom examined quantitatively in previous studies, can serve as early predictors of haze.

Furthermore, the local terrain, which is hilly, crucially affects the formation of haze. During autumn, stable weather conditions prevail on the North China Plain, but the mountain-plain breeze drives strong local wind circulation in the BTH region. The wind that develops on the plain during the day transports and converges pollutants along the mountains to Beijing and the adjacent areas, whereas the wind that arises from the mountains at night, which is weaker, produces only limited diffusion. Thus, the mountain-plain breeze, like the tides, pushes pollutants to areas along the mountains, especially toward the northernmost city, Beijing, in the daytime, resulting in a daily rise in pollutants with an increasing or nearly unchanged MLH. Our results indicate that pollutant transport can contribute to haze episodes during autumn in spite of a stable atmosphere.

Additionally, the mountain-plain local topography in conjunction with easterly winds can induce the formation and dissipation of haze. The mountains block the easterly winds, producing highaltitude vertical circulation that uplifts pollutants from the surface along the mountains, transports them to the southeast, and then brings them back to the surface. With subsequent increased southerly winds, the pollutants are carried along the surface and at higher altitudes to Beijing 
once again-where intense downward air motion mixes and compresses them into the low atmospheric layers - ultimately aggravating the next haze episode.

This study provides insight into the long-lasting pollution episodes that frequently affect the Beijing area. The concentration of the $\mathrm{PM}_{2.5}$ displays an overall increasing trend on the North China Plain under stable synoptic weather conditions, but variation in the dynamic conditions can lead to different spatial and temporal distributions of this pollutant during haze episodes. Haze forecasting therefore necessitates three-dimensional observation and analysis of the meteorological conditions. The formation of the super-low boundary layer, for example, during EP3, also merits further investigation. Finally, secondary $\mathrm{PM}_{2.5}$ formation becomes a key factor during stable periods with high $\mathrm{RH}$, but assessing its effects requires chemical composition and size distribution data with sufficient temporal resolutions. Future research can achieve this goal by obtaining more comprehensive observation data and applying advanced numerical simulation techniques.

\section{ACKNOWLEDGEMENTS}

This work was supported by the Natural Science Foundation of Beijing Municipality (8161004), the National Natural Science Foundation of China (41305130), and Beijing Major Science and Technology Project (Z181100005418014). We thank LAPC for providing meteorological observation data.

\section{REFERENCES}

Chen D., Liu, Z., Fast, J., Ban, J. (2016). Simulations of Sulfate-Nitrate-Ammonium (SNA) aerosols during the extreme haze events over Northern China. Atmos. Chem. Phys. 16, 10707-10724. https://doi.org/10.5194/acp-16-10707-2016

Chen, F., Dudhia, J. (2001). Coupling an advanced land surface hydrology model with the Penn StateNCAR MM5 modeling system. Part I: Model implementation and sensitivity. Mon. Weather Rev. 129, 569-585. https://doi.org/10.1175/1520-0493(2001)129<0569:CAALSH>2.0.CO;2

Chen, Z., Cheng, S., Li, J., Guo, X., Wang, W., Chen, D. (2008). Relationship between atmospheric pollution processes and synoptic pressure patterns in northern China. Atmos. Environ. 42, 6078-6087. https://doi.org/10.1016/j.atmosenv.2008.03.043

Chou, M.D., Suarez, M.J. (1994). An efficient thermal infrared radiation parameterization for use in general circulation models. NASA Tech. Memorandum 104606 - Vol. 3, NASA, Goddard Space Flight Center, Greenbelt, MD, USA.

Du, H., Li, J., Chen, X., Wang, Z., Sun, Y., Fu, P., Li, J., Gao, J., Wei, Y. (2019). Modeling of aerosol property evolution during winter haze episodes over a megacity cluster in northern China: Roles of regional transport and heterogeneous reactions of $\mathrm{SO}_{2}$. Atmos. Chem. Phys. 19, 93519370. https://doi.org/10.5194/acp-19-9351-2019

Emeis, S., Schäfer, K., Münkel, C., Friedl, R., Suppan, P. (2012). Evaluation of the interpretation of ceilometer data with RASS and radiosonde data. Boundary Layer Meteorol. 143, 25-35. https://doi.org/10.1007/s10546-011-9604-6

Fernald, F.G. (1984). Analysis of atmospheric lidar observation: Some comments. Appl. Opt. 23, 652-653. https://doi.org/10.1364/A0.23.000652

Geiß, A., Wiegner, M., Bonn, B., Schäfer, K., Forkel, R., von Schneidemesser, E., Münkel, C., Chan, K.L., Nothard, R. (2017). Mixing layer height as an indicator for urban air quality? Atmos. Meas. Tech. 10, 2969-2988. https://doi.org/10.5194/amt-10-2969-2017

Guo, J., Miao, Y., Zhang, Y., Liu, H., Li, Z., Zhang, W., He, J., Lou, M., Yan, Y., Bian, L., Zhai, P. (2016). The climatology of planetary boundary layer height in China derived from radiosonde and reanalysis data, Atmos. Chem. Phys. 16, 13309-13319. https://doi.org/10.5194/acp-16-133092016

Guo, S., Hu, M., Zamora, M.L., Peng, J., Shang, D., Zheng, J., Du, Z., Wu, Z., Shao, M., Zeng, L., Molina, M.J., Zhang, R. (2014). Elucidating severe urban haze formation in China. PNAS 111 17373-17378. https://doi.org/10.1073/pnas.1419604111

Han, B., Zhang, R., Yang,W., Bai, Z., Ma, Z., Zhang,W. (2016). Heavy haze episodes in Beijing during 
January 2013: Inorganic ion chemistry and source analysis using highly time-resolved measurements from an urban site. Sci. Total Environ. 544:319-329. https://doi.org/10.1016/j. scitotenv.2015.10.053

Hong, S.Y., Noh, Y., Dudhia, J. (2006). A new vertical diffusion package with an explicit treatment of entrainment processes. Mon. Weather Rev. 134, 2318-2341. https://doi.org/10.1175/MWR 3199.1

Hua, Y., Wang, S., Wang, J, Jiang, J., Zhang, T., Song, Y., Kang, L., Zhou, W., Cai, R., Wu, D., Fan, S., Wang, T., Tang, X., Wei, Q., Sun, F., Xiao, Z. (2016). Investigating the impact of regional transport on $\mathrm{PM}_{2.5}$ formation using vertical observation during APEC 2014 Summit in Beijing. Atmos. Chem. Phys. 16, 15451-15460. https://doi.org/10.5194/acp-16-15451-2016

Huang, S. (2018). Air pollution and control: Past, present and future. Chin. Sci. Bull. 63, 895-919. https://doi.org/10.1360/N972017-01271 (in Chinese)

Ji, D.S., Li, L., Wang, Y.S., Zhang, J.K., Cheng, M.T., Sun, Y., Liu, Z.R., Wang, L., Tang, G., Hu, B., Chao, N., Wen, T.X., Miao, H. Y. (2014). The heaviest particulate air-pollution episodes occurred in northern China in January, 2013: Insights gained from observation. Atmos. Environ. 92, 546556. https://doi.org/10.1016/j.atmosenv.2014.04.048

Jia, Y., Rahn, K.A., He, K., Wen, T., Wang, Y. (2008). A novel technique for quantifying the regional component of urban aerosol solely from its sawtooth cycles. J. Geophys. Res. 113, D21309. https://doi.org/10.1029/2008JD010389

Kotthaus, S., O'Connor, E., Münkel, C., Charlton-Perez, C., Haeffelin, M., Gabey, A.M., Grimmond, C.S.B. (2016). Recommendations for processing atmospheric attenuated backscatter profiles from Vaisala CL31 ceilometers. Atmos. Meas. Tech. 9, 3769-3791. https://doi.org/10.5194/am t-9-3769-2016

Li, M., Liu, H., Geng, G., Hong, C., Liu, F., Song, Y., Tong, D., Zheng, B., Cui, H., Man, H., Zhang, Q., He, K. (2017). Anthropogenic emission inventories in China: A review. Natl. Sci. Rev. 4, 834866. https://doi.org/10.1093/nsr/nwx150

Liu, Q., Jia, X. C., Quan, J. N., Li, J., Li, X., Wu, Y., Chen, D., Wang, Z.F., Liu, Y. (2019). New positive feedback mechanism between boudnary layer meteorology and secondary aerosol formation during server haze events. Sci. Rep. 8, 6095. https://doi.org/10.1038/s41598-018-24366-3

Liu, Z., Hu, B., Liu, Q., Sun, Y., Wang Y. (2014). Source apportionment of urban fine particle number concentration during summertime in Beijing, Atmos. Environ. 96, 359-369. https://doi.org/10.1016/j.atmosenv.2014.06.055

Luan, T., Guo, X., Guo, L., Zhang, T. (2018). Quantifying the relationship between PM 2.5 concentration, visibility and planetary boundary layer height for long-lasting haze and foghaze mixed events in Beijing. Atmos. Chem. Phys. 18, 203-225. https://doi.org/10.5194/acp18-203-2018

Miao, S., Dou, J., Chen, F., Li, J., Li, A. (2012). Analysis of observations on the urban surface energy balance in Beijing. Sci. China Earth Sci. 55, 1881-1890. https://doi.org/10.1007/s11430-0124411-6

Miao, Y., Hu, X., Liu, S., Qian, T., Xue, M., Zheng, Y., Wang, S. (2015). Seasonal variation of local atmospheric circulations and boundary layer structure in the Beijing-Tianjin-Hebei region and implications for air quality. J. Adv. Model. Earth Syst. 7, 1602-1626. https://doi.org/10.1002/2 $015 \mathrm{MS000522}$

Mlawer, E.J., Taubman, S.J., Brown, P.D., Iacono, M.J., Clough, S.A. (1997). Radiative transfer for inhomogeneous atmospheres: RRTM, a validated correlated-k model for the longwave. J. Geophys. Res. 102, 16663-16682. https://doi.org/10.1029/97JD00237

Münkel, C., Eresmaa, N., Räsänen, J., Karppinen, A. (2007). Retrieval of mixing height and dust concentration with lidar ceilometers. Boundary Layer Meteorol. 124, 117-128. https://doi.org/ 10.1007/s10546-006-9103-3

Quan, J. N., Liu, Q., Li, X., Gao, Y., Jia, X., Sheng, J., Liu, Y. (2015). Effect of heterogeneous aqueous reactions on the secondary formation of inorganic aerosols during haze events. Atmos. Environ. 122, 306-312. https://doi.org/10.1016/j.atmosenv.2015.09.068

Su, T., Li, Z., Kahn, R. (2018). Relationships between the planetary boundary layer height and surface pollutants derived from lidar observations over China: Regional pattern and influencing factors. Atmos. Chem. Phys. 18, 15921-15935. https://doi.org/10.5194/acp-18-15921-2018

Sugimoto, N., Matsui, I., Liu, Z., Shimizu, A., Asai, K., Yoneyama, K., Katsumata, M. (2001). 
Latitudinal distribution of aerosols and clouds in the western Pacific observed with a lidar on board the Research Vessel Mirai. Geophys. Res. Lett. 28, 4187-4190. https://doi.org/10.1029/ 2001GL013510

Sun, Y.L., Jiang, Q., Wang, Z., Fu, P., Li, J., Yang, T., Yin, Y. (2014). Investigation of the sources and evolution processes of severe haze pollution in Beijing in January 2013. J. Geophys. Res. 119, 4380-4398. https://doi.org/10.1002/2014JD021641

Sun, Y., Wang, Z., Wild, O., Xu, W., Chen, C., Fu, P., Du, W., Zhou, L., Zhang, Q., Han, T., Wang, Q., Pan, X., Zheng, H., Li, J., Guo, X., Liu, J., Worsnop, D.R. (2016). “APEC Blue”: Secondary aerosol reductions from emission controls in Beijing. Sci. Rep. 6, 20668. https://doi.org/10.1038/srep2 0668

Tang, G., Zhu, X., Hu, B., Xin, J., Wang, L., Münkel, C., Mao, G., Wang, Y. (2015). Impact of emission controls on air quality in Beijing during APEC 2014: lidar ceilometer observations. Atmos. Chem. Phys. 15, 12667-12680. https://doi.org/10.1016/j.atmosenv.2019.04.050

Tang, G., Zhang, J.Q., Zhu, X.W., Song, T., Münkel, C., Hu, B., Schäfer, K., Liu, Z., Zhang, J., Wang, L., Xin, J., Suppan, P., Wang, Y. (2016). Mixing layer height and its implications for air pollution over Beijing, China. Atmos. Chem. Phys. 16, 2459-2475. https://doi.org/10.5194/acp-16-24592016

Tao, M.H., Chen, L.F., Xiong, X.Z., Zhang, M.G., Ma, P.F., Tao, J.H., Wang, Z.F. (2014). Formation process of the widespread extreme haze pollution over northern China in January 2013: Implications for regional air quality and climate. Atmos. Environ. 98, 417-425. https://doi.org/ 10.1016/j.atmosenv.2014.09.026

Thompson,G., Field, P.R., Rasmussen, R.M., Hall, W.D. (2008). Explicit forecasts of winter precipitation using an im-proved bulk microphysics scheme. Part II: Implementation of a new snow parameterization. Mon. Weather Rev. 136, 5095-5115. https://doi.org/10.1016/j.atmos env.2019.117098

Xu, L.L., Duan, F.K., He, K.B., Ma, Y.L., Zhu, L.D., Zheng, Y.X., Huang, T., Kimoto, T., Ma, T., Li, H., Ye, S., Yang, S., Sun, Z., Xu, B. (2017). Characteristics of the secondary water-soluble ions in a typical autumn haze in Beijing. Environ. Pollut. 227, 296-305. https://doi.org/10.1016/j.atmos env.2019.117098

Xu, W.Q., Sun, Y.L., Chen, C., Du, W., Han, T.T., Wang, Q.Q. , Fu, P.Q., Wang, Z.F., Zhao, X.J., Zhou, L.B., Ji, D.S., Wang, P.C., Worsnop, D.R. (2015). Aerosol composition, oxidation properties, and sources in Beijing: Results from the 2014 Asia-Pacific Economic Cooperation summit study. Atmos. Chem. Phys. 15, 13681-13698. https://doi.org/10.5194/acp-15-13681-2015

Yang, Y.R., Liu, X.G., Qu, Y., An, J.L., Jiang, R., Zhang, Y.H., Sun, Y.L., Wu, Z.J., Zhang, F., Xu, W.Q., Ma, Q.X. (2015). Characteristics and formation mechanism of continuous hazes in China: A case study during the autumn of 2014 in the North China Plain. Atmos. Chem. Phys. 15, 8165-8178. https://doi.org/10.5194/acp-15-8165-2015

Ye, X.X., Song, Y., Cai, X.H., Zhang, H.S. (2016). Study on the synoptic flow patterns and boundary layer process of thesevere haze events over the North China Plain in January 2013. Atmos. Environ. 124, 129-145. https://doi.org/10.1016/j.atmosenv.2015.06.011

Yin, X.M., Sun, Z.B., Miao, S.G., Yan, Q., Wang, Z.S., Shi, G., Li, Z.M., Xue, W. (2019). Analysis of abrupt changes in the $\mathrm{PM}_{2.5}$ concentration in Beijing during the conversion period from the summer to winter half-year in 2006-2015. Atmos. Environ. 200, 319-328. https://doi.org/10.1 016/j.atmosenv.2018.11.057

Zaveri, R.A., Peters, L.K. (1999). A new lumped structure photochemicalmechanism for large-scale applications. J. Geophys. Res. 104, 30387-30415. https://doi.org/10.1029/1999JD900876

Zaveri, R.A., Easter, R.C., Fast, J.D., Peters, L.K. (2008). Model forSimulating Aerosol Interactions and Chemistry (MOSAIC). J. Geophys. Res. 113, D13204, https://doi.org/10.1029/2007JD008782

Zhang, Q., Streets, D.G., Carmichael, G.R., He, K.B., Huo, H., Kannari, A., Klimont, Z., Park, I.S., Reddy, S., Fu, J.S., Chen, D., Duan, L., Lei, Y., W ang, L.T., Yao, Z.L. (2009). Asian emissions in 2006 for the NASA INTEX-B mission. Atmos. Chem. Phys. 9, 5131-5153. https://doi.org/10.519 4/acp-9-5131-2009

Zhao, P., Zhang, X., Xu, X., Zhao, X. (2011). Long-term visibility trends and characteristics in the region of Beijing, Tianjin, and Hebei, China. Atmos. Res. 101, 711-718. https://doi.org/10.101 6/j.atmosres.2011.04.019

Zhao, X., Zhang, X., Xu, X., Xu, J., Meng, W., Pu, W. (2009). Seasonal and diurnal variations of 
ambient $\mathrm{PM}_{2.5}$ concentration in urban and rural environments in Beijing. Atmos. Environ. 43, 2893-2900. https://doi.org/10.1016/j.atmosenv.2009.03.009

Zheng, G.J., Duan, F.K., Su, H., Ma, Y.L., Cheng, Y., Zheng, B., Zhang, Q., Huang, T., Kimoto, T., Chang, D., Pöschl, U., Cheng, Y.F., He, K.B. (2015). Exploring the severe winter haze in Beijing: the impact of synoptic weather, regional transport and heterogeneous reactions. Atmos. Chem. Phys. 15, 2969-2983. https://doi.org/10.5194/acp-15-2969-2015

Zhong, J.T., Zhang, X.Y., Dong,Y.S., Wang, Y.Q., Liu, C., Wang, J.Z., Zhang, Y.M., Che, H.Z. (2018). Feedback effects of boundary-layer meteorological factors on cumulative explosive growth of $\mathrm{PM}_{2.5}$ during winter heavy pollution episodes in Beijing from 2013 to 2016. Atmos. Chem. Phys. 18, 247-258. https://doi.org/10.5194/acp-18-247-2018 